\title{
An Experimental Approach On Aerodynamic Stability Of A Cable-Stayed Cantilever Bridge
}

\author{
Fumitaka Yoshizumi ${ }^{1)}$ and Hiroo Inoue ${ }^{1)}$
}

1) Engineering Department, Steel Structure \& Logistic Systems Headquarters, Mitsui Engineering \& Shipbuilding, Co., Ltd, Tokyo 104-8439, Japan

\section{INTRODUCTION}

The cable-stayed bridge was constructed in the marine park "Sea Road Yawatahama" to access the pontoon for fishing (Fig. 1). This bridge is a very unique cable-stayed bridge with special features as follows.

1) Cantilever type deck beam

2) Gangway structure covered with mesh panel at the beam edge

3) Bluff deck section with 2-edge girder and grating

4) Non-uniform deck section along the bridge axis

Through those features, it seems to be rather difficult to predict the aerodynamic instability problems than other normal cable-stayed bridges. Therefore 3D and 2D wind tunnel tests were carried out in order to clear the aerodynamic phenomena of this bridge. In addition, the characteristics of the site wind and the real bridge mode were measured to compare wind and modal conditions of the 3D wind tunnel test with those of the real site.

Between those wind tunnel tests and site measurements, this paper shows mainly the results of wind tunnel tests. Wind tunnel tests were consisted of the 2D tests for the deck section near the beam edge and the 3D tests using 3D model with elastic deck beam. The former 2D tests include 3-component force balance test and spring supported test that cleared the basic aerodynamic characteristics of the deck section. Through the latter test, the response of the non-uniform deck beam was measured directly and gust response was observed. Usual 3D galloping analysis and gust-response analysis using the results of 2D deck section tests were carried out. The responses obtained from those analyses and from the 3D tests were compared.

\section{WIND TUNNEL TEST}

\section{2-1. 2D Wind Tunnel Test of the Deck Section}

The 2D deck section model is $1 / 12$ scale and simulates the section near the edge $(62[\mathrm{~m}]$ point from the tower). Aerodynamic forces in static condition and unsteady aerodynamic characteristics were measured.

1) Aerodynamic characteristics in static condition

The original and the closed-grating section's aerodynamic coefficients in static condition are shown in Fig. 2. The $\mathrm{C}_{\mathrm{L}}$ of the closed-grating section has rather steep negative slope than that of the original section. Therefore the grating seems to bring aerodynamic stability in heaving motion from the viewpoint of quasi-steady theory.

2) Unsteady aerodynamic characteristics

Unsteady aerodynamic characteristics were tested by the heaving/torsional 1 degree of freedom (DOF) spring supported tests under smooth flow. The normalized aerodynamic derivatives ${ }^{1)}$ defined as follows are shown in Fig. 3 and 4, 


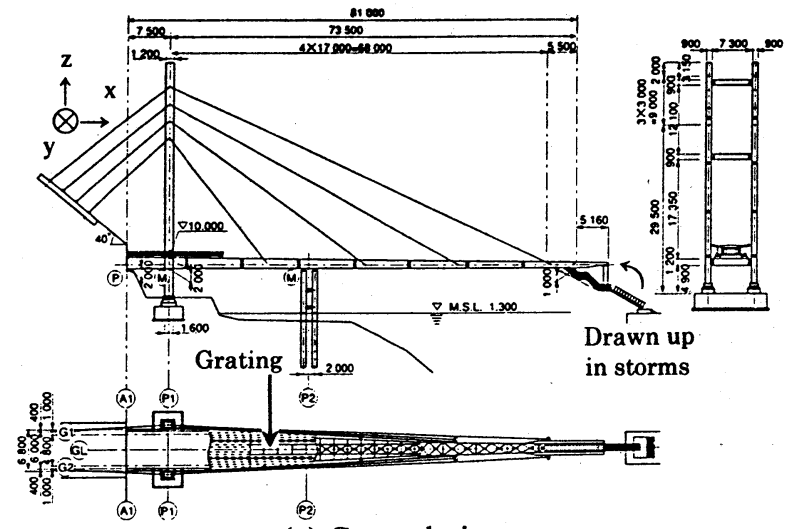

(a) General view

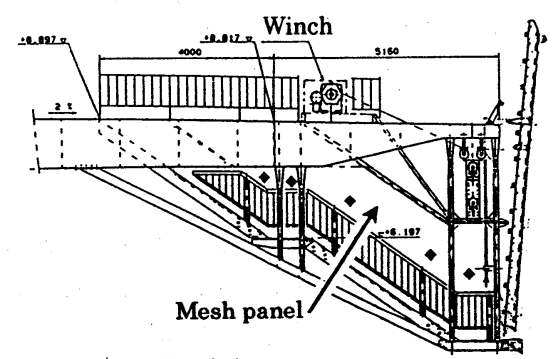

(b) Detail of the gangway structure

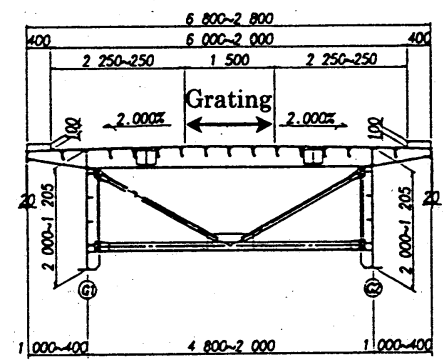

(c) The deck section

Fig. 1 General view and the deck section

$$
\begin{aligned}
& \mathrm{L}=\frac{1}{2} \rho \mathrm{U}^{2}(2 \mathrm{~b})\left\{\mathrm{kH}_{1} * \frac{\dot{\eta}}{\mathrm{U}}+\mathrm{k}^{2} \mathrm{H}_{4}^{*} \frac{\eta}{\mathrm{b}}\right\}, \\
& \mathrm{M}=\frac{1}{2} \rho \mathrm{U}^{2}\left(2 \mathrm{~b}^{2}\right)\left\{\mathrm{kA}_{2} \cdot \frac{\mathrm{b} \dot{\phi}}{\mathrm{U}}+\mathrm{k}^{2} \mathrm{~A}_{3}^{*} \phi\right\} .
\end{aligned}
$$

L: unsteady lift force per unit span length, $M$ : unsteady moment force per unit span length, $\rho$ : air density, $U$ : wind velocity, b: half chord length $(=\mathrm{B} / 2), \eta$ : vertical displacement, $\phi$ : torsional displacement, $k$ : reduced frequency $(k=b \omega / U)$, $\omega$ : circular frequency

The aerodynamic derivatives $\mathrm{H}_{1}{ }^{*}$ and $\mathrm{A}_{2}{ }^{*}$ can make the judgement of heaving/torsional $1 \mathrm{DOF}$ instability. $\mathrm{H}_{1}{ }^{*}$ of the original section keeps near zero to the extent of high wind speed region. Therefore the

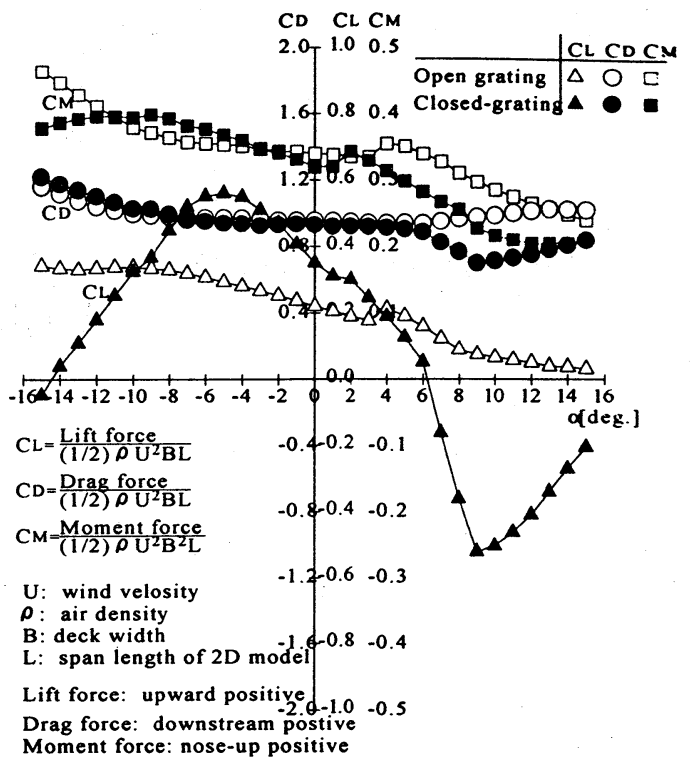

Fig. 2 Aerodynamic coefficient in static condition

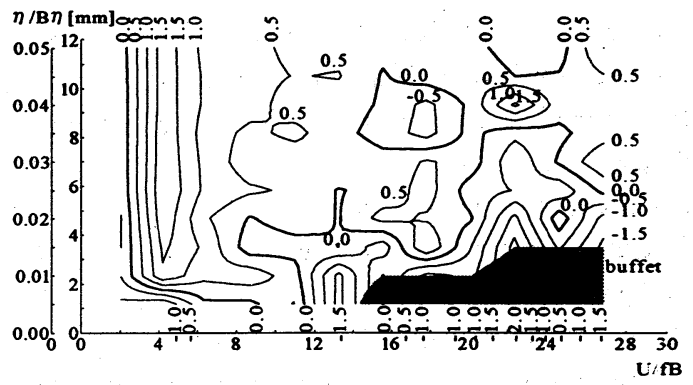

Fig. $3(1) \mathrm{H}_{1}^{*}$ of the open grating section

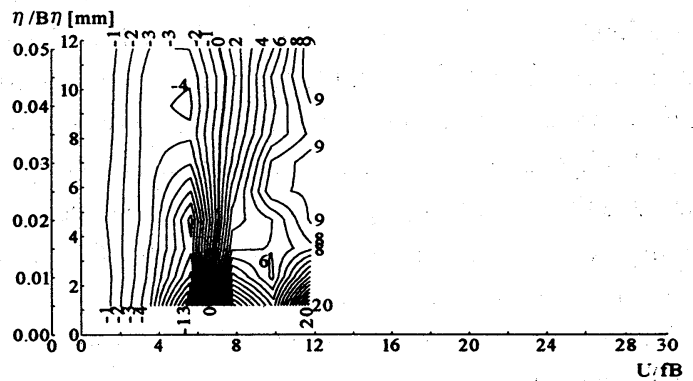

Fig. $3(2) \mathrm{H}_{1}^{*}$ of the closed-grating section aerodynamic force has little effect on damping factor in 1 DOF heaving motion. On the other hand, $\mathrm{H}_{1}{ }^{*}$ of the closed-grating section has positive value, that corresponds to possibility of galloping. That shows the grating has an effect of stability in heaving motion. $\mathrm{A}_{2}{ }^{*}$ of the original section keeps negative, that is, the section has stable aerodynamic force in $1 \mathrm{DOF}$ torsional motion. 


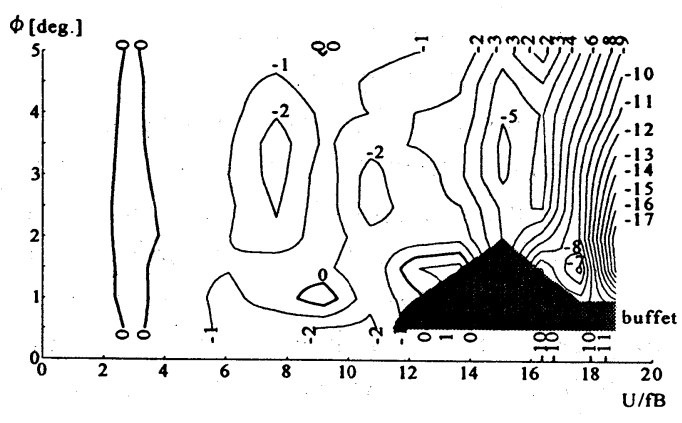

Fig. $4 \mathrm{~A}_{2}^{*}$ of the open grating section

Table 1 Eigen-value analysis and test conditions

\begin{tabular}{|c|c|c|c|c|c|c|}
\hline \multirow{2}{*}{ Mode Order } & \multirow{2}{*}{$\begin{array}{l}\text { Freq. } \\
{\left[\mathrm{Hz}_{2}\right]}\end{array}$} & \multirow{2}{*}{$\begin{array}{l}\text { Period } \\
\text { [sec.] }\end{array}$} & \multirow{2}{*}{$\begin{array}{c}\text { ※Generalized } \\
\text { Mass }\end{array}$} & \multicolumn{2}{|c|}{ Equivalent Mass } & \multirow{2}{*}{\begin{tabular}{|c|} 
Mode \\
H: Horizontal \\
V: Vertical
\end{tabular}} \\
\hline & & & & megy & $\frac{\operatorname{meg} z}{[\mathrm{t} / \mathrm{m}]}$ & \\
\hline 1 & 0.696 & 1.437 & 25.72 & 1.914 & - & Deck H. 1st \\
\hline 2 & 0.905 & 1.1 & 22.49 & - & 2.247 & V. 1st \\
\hline 3 & 1.233 & 4 & 43.67 & 1.396 & - & Tower 1 st \\
\hline 4 & 2.332 & & 24.38 & - & 1.170 & Deck V. 2nd \\
\hline 5 & 2.883 & 0.347 & 38.20 & 1.329 & - & Deck H. 2nd \\
\hline
\end{tabular}

3D Test Condition

\begin{tabular}{|c|c|c|c|c|}
\hline \multicolumn{5}{|c|}{ Model Condition } \\
\hline Mode Order & $\begin{array}{l}\text { Freq. } \\
{\left[\mathrm{Hz}_{\mathrm{z}}\right]}\end{array}$ & $\begin{array}{l}\text { Period } \\
\text { [sec.] }\end{array}$ & Logarithmic Damping & Mode \\
\hline & $5.33 \sim 5.34$ & $0.188 \sim 0.187$ & $0.012 \sim 0.013$ & Deck H. 1st \\
\hline 2 & $6.33 \sim 6.35$ & $0.158 \sim 0.157$ & $0.017 \sim 0.018$ & Deck V. Ist \\
\hline \multicolumn{5}{|c|}{ Turbulence Condition } \\
\hline \multirow{2}{*}{ Intensity } & II & $11.2 \sim 13.8$ & & \\
\hline & $I w[x]$ & $7.6 \sim 8.6$ & & \\
\hline $\begin{array}{l}\text { Scalo (Wind } \\
\text { Direction) }\end{array}$ & $\frac{\operatorname{Lux}[m]}{\operatorname{Lwx}[m]}$ & 0.238 & $\begin{array}{l}\text { Equivalent Scale in the } \\
\text { Prototype }\end{array}$ & $\frac{14.28}{3.78}$ \\
\hline
\end{tabular}

2-2. 3D Wind Tunnel Test

The 3D model is $1 / 60$ scale model and made up of the elastic deck beam, the rigid tower and cables with springs installed at the tower side ends. The $1^{\text {st }}$ horizontal and vertical mode shapes were simulated to them obtained by eigen-value analysis. The responses of the deck beam were measured both in smooth flow and turbulent flow. Test conditions are shown in Table 1. In smooth flow, the deck beam deformed statically in horizontal direction and dynamic instabilities as vortex induced vibration and galloping were not observed as shown in Fig. 5 (1). In turbulent flow, the gust response occurred in addition to static deformation but other dynamic phenomena were not observed as shown in Fig. 5 (2). The case where the deck grating was closed was tested under smooth flow to survey the effect of the grating, but no dynamic phenomenon was observed. Besides that, the case where the gangway structure was taken away was tested under turbulent flow and the gust response became about $2 / 3$ of the original case as shown in Fig. 5 (2).

\section{2-3. Comparison between 2D and 3D Tests}

1) Damping ratio in smooth flow

Damping ratio of the vertical $1^{\text {st }}$ mode of 3D model in smooth flow is estimated by $\mathrm{H}_{1}{ }^{*}$ of the $2 \mathrm{D}$ deck

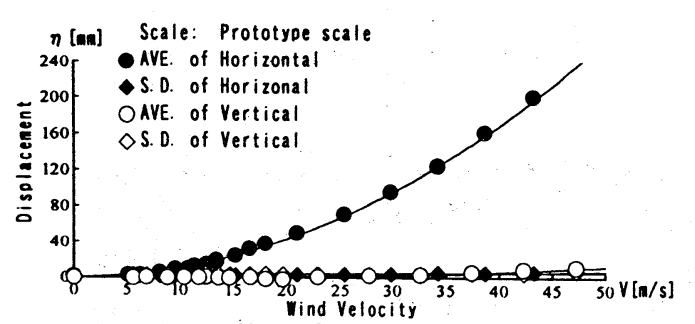

(1) In Smooth Flow

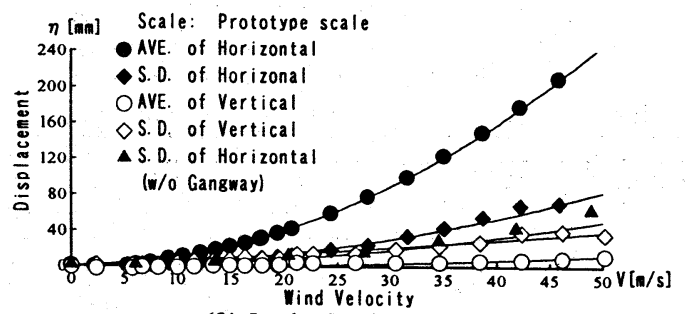

(2) In the Turbulent Flow

Fig. 5 Response at the cantilever edge in 3D wind tunnel tests

sections and Den Hartog condition considering the mode shape.

<From unsteady aerodynamic coefficient>

$$
\zeta=\frac{\zeta_{0} \omega_{0}}{\omega}-\frac{\rho b^{2} \mathrm{H}_{1}^{*} \mathrm{eq}}{2 \mathrm{~m}_{\mathrm{eq}}},
$$

where

$$
\begin{aligned}
& \omega=\frac{\omega_{0}}{\sqrt{1+\frac{\rho b^{2} \mathrm{H}_{4}^{*}{ }^{*} \mathrm{~m}}{\mathrm{~m}_{\mathrm{eq}}}}} \\
& \mathrm{H}_{1,4}^{*} \text { eq }=\frac{\sum_{\mathrm{i}(\mathrm{G})} \mathrm{H}_{1,4}^{*}\left(\mathrm{U}^{*}, \phi_{\mathrm{i}} \mathrm{q}_{0} / \mathrm{B}\right) \phi_{\mathrm{i}}{ }^{2} \mathrm{l}_{\mathrm{i}}}{\sum_{\mathrm{i}(\mathrm{G})} \phi_{\mathrm{i}}{ }^{2} \mathrm{l}_{\mathrm{i}}} .
\end{aligned}
$$

$<$ From steady aerodynamic derivatives $>$

$$
\zeta=\zeta_{0}+\frac{\rho U B}{4 m_{e q} \omega_{0}}\left(\frac{d_{L}}{d \alpha}+C_{D}\right),
$$

$\zeta$ : damping ratio, $\zeta_{0}$ : structural damping ratio, $\omega$ : circular frequency, $\omega_{0}$ : structural circular frequency, $\rho$ : air density, b: half chord length, $\mathrm{m}_{\mathrm{eq}}$ : equivalent mass of the $1^{\text {st }}$ mode, $U^{*}$ : reduced velocity, $\phi_{i}$ : mode of member $i$ of the $1^{\text {st }}$ mode, $q_{0}$ : amplitude of generalized coordinate, $\mathrm{l}_{\mathrm{i}}$ : length of member $i, \alpha$ : attack angle

$\Sigma_{\mathrm{i}(\mathrm{G})}$ : sum of deck girder members

$\mathrm{V}-\boldsymbol{\delta}$ (logarithmic damping) characteristics obtained from eq. (2) and (3) are compared to that of 3D test in Fig. 6. In both cases of the original deck section 


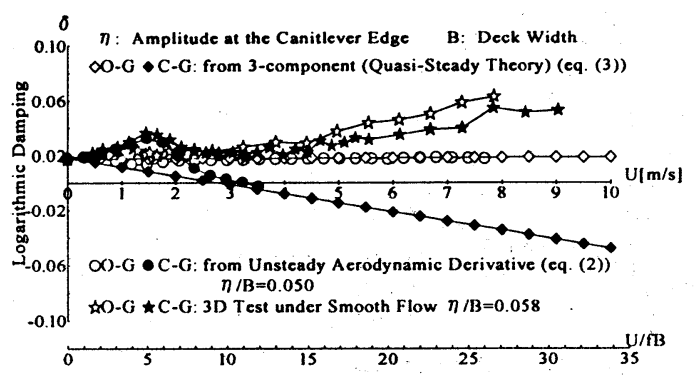

Fig. 6 Damping ratio in smooth flow

Table 2 Conditions of gust response analyses

\begin{tabular}{|c|c|c|}
\hline & Horizontal lst mode \\
\hline \multicolumn{2}{|c|}{ Generalized Mass Ms* $\left[\mathrm{kg} \mathrm{m}^{*} 2\right]$} & 0.112 \\
\hline \multicolumn{2}{|c|}{ Structural Damping Ratio $\zeta s$} & 0.00189 \\
\hline \multicolumn{2}{|c|}{ Natural Freg. fs $[\mathrm{Hz}]$} & 5.34 \\
\hline \multicolumn{2}{|c|}{ Aerodynamic Damping } & Quasi-steady \\
\hline \multirow[b]{2}{*}{ 3-Component } & Deck & $\begin{array}{l}\mathrm{CL}=0.220 \mathrm{CD}=0.957 \\
\mathrm{dCL} / \mathrm{d} \alpha=-0.925\end{array}$ \\
\hline & $\begin{array}{l}\text { Gangway } \\
\text { (Projection Area: } \\
\text { 28.2[m²] }\end{array}$ & $C D=1.6$ \\
\hline \multicolumn{2}{|c|}{ Turbulent Intensity Horizontal $\mathrm{lu}[\boldsymbol{\Psi}]$} & 12.5 \\
\hline \multicolumn{2}{|c|}{ P.S.D. of Turbulence } & Karman Type \\
\hline \multicolumn{2}{|c|}{$\begin{array}{r}\text { Turbulence Scale (Wind } \\
\text { Direction) }\end{array}$} & 0.238 \\
\hline \multicolumn{2}{|l|}{ Spatial Correlation } & Exp. Type (Decay Factor $=8$ ) \\
\hline \multicolumn{2}{|l|}{ Aero-Admittance } & Quasi-steady \& Davenport \\
\hline
\end{tabular}

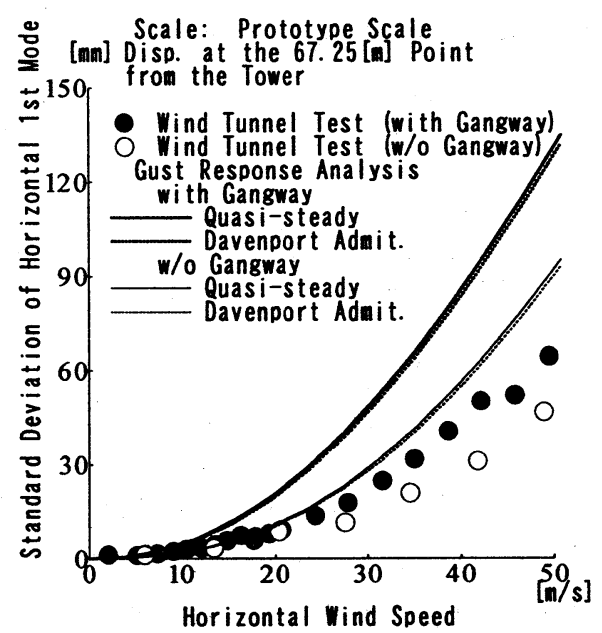

Fig. 7 Result of gust response analyses

(=open grating section: $O-G$ ) and closed-grating section (C-G), the damping factor of 3D tests cannot be evaluated from eq. (2) or (3) using $2 D$ deck section characteristics. This inconsistency seems to be caused by disregarding of the effect of the gangway structure at the beam edge. In both cases, the damping factors of 3D tests are larger than that obtained by using only deck section damping (eq. (2) or (3)). Therefore the gangway structure seems to contribute to aerodynamic stabilization in vertical motion.

2) Gust response in turbulent flow

The gust response analyses ${ }^{2)}$ of horizontal $1^{\text {st }}$ mode were carried out for both the original case and the gangway structure-disregarded case under the condition as shown in Table 2. In the original case, the aerodynamic force of the gangway was given by projection area and supposed $C_{D}$ value. The results are compared to those of the 3D tests in Fig. 7. In both cases, the analysis overestimates the response value. It seems to be possible to estimate the gust response by analysis provided that the aerodynamic admittances both of the deck and the gangway structure were cleared.

\section{CONCLUSION}

(1) The 2D deck section tests cleared that the grating brings aerodynamic stability in heaving motion. The deck section with grating doesn't have unstable aerodynamic force in heaving 1 DOF motion and stable aerodynamic force in torsional 1 DOF motion.

(2) The 3D wind tunnel tests were carried out for the cable-stayed bridge that is very unique from a viewpoint of wind engineering. In the tests, large horizontal static deformation and gust response were observed.

(3) The aerodynamic property of gangway structure has much effect on unsteady property in vertical $1^{\text {st }}$ mode of $3 \mathrm{D}$ full model bridge. The gust response analysis overestimates the 3D response and this inconsistency seems to be due to the uncertainty of aerodynamic admittance.

On the basis of the wind tunnel test results, wind characteristics and the gust response were measured in the site. Through the measurements, the consistency between the model and the real bridge was confirmed, and the fatigue damage of the deck caused by the gust response was calculated and it was estimated that there is little or no possibility of fatigue collapse.

Reference

1) Scanlan, R.H. and Tomko, J.J. 1971, Airfoil and Bridge Deck Flutter Derivatives, ASCE J. Eng. Mech. Div., Vol. 97, EM6, pp. 1717-1737.

2) Katsuchi, H., Saeki, S., Miyata, T. and Sato, H. 1998, Analytical Assessment in Wind-resistant Design of Long-span Bridges in Japan, Bridge Aerodynamics, Larsen \& Esdahl (eds), Balkema, Rotterdam, ISBN 90 5410 9610, pp. 87-98.

Key words: cable-stayed bridge, cantilever bridge, wind tunnel test, gust response 


\title{
Aerodynamic performance of improved shallow $\pi$ shape bridge deck
}

\author{
KUBO, Yoshinobu ${ }^{1)}$, KIMURA, Kichiro ${ }^{2)}$, SADASHIMA, Kensuke ${ }^{3)}$, OKAMOTO, Yuzo ${ }^{4)}$, \\ YAMAGUCHI, Eiki ${ }^{5)}$ and KATO, Kusuo ${ }^{6)}$
}

\section{1),2),3),5),6) Department of Civil Engineering, Kyushu Institute of Technology, Professor, Associate Professor, Graduate Student, Associate Professor, Research Associate, Fukuoka, JAPAN \\ 4) Civil Engineering \& Construction Division, Sagamihara Office, Nippon Steel, Kanagawa, JAPAN}

\section{INTRODUCTION}

The $\pi$ section deck is one of the most economical choices for cable-supported bridges. However, it tends to be vulnerable to wind-induced vibration and has been thought to be not suitable for long-span bridges without substantial modification of the sectional shape using aerodynamic appendages. On the other hand, by changing the location of the two main girders, the aerodynamic stability was found to improve possibly due to the interaction of the separated flow from the leading edge of the floor deck with the flange of the windward main girder. Even with solid traffic barriers, by setting the barrier so that its upper edge interacts with the separated flow from the leading edge of the floor deck on the upper side, the aerodynamic performance was $\operatorname{good}^{1)}$.

These experimental results were obtained when the angle of attack was $0^{\circ}$, i.e., approaching flow direction was horizontal. In this study, aerodynamic performance of such improved $\pi$ shape bridge deck under wind with various angles of attack is studied and the characteristics of wind-induced response are also discussed.

\section{WIND TUNNEL EXPERIMENT}

The experiment was conducted in a closed circuit wind tunnel with square test section of $1.07 \mathrm{~m}$ wide and high. A sectional model as shown in Fig. 1 was supported by springs that allowed heaving and torsional vibration. The mass and polar moment of inertia per unit length of the model were $7.00 \mathrm{~kg} / \mathrm{m}$ and $0.138 \mathrm{~kg} \mathrm{~m} \mathrm{~m}^{2} / \mathrm{m}$, respectively. Natural frequencies for heaving and torsional vibrations were 2.31 and $4.29 \mathrm{~Hz}$, and the logarithmic structural dampings were 0.0038 and 0.0015 , respectively.

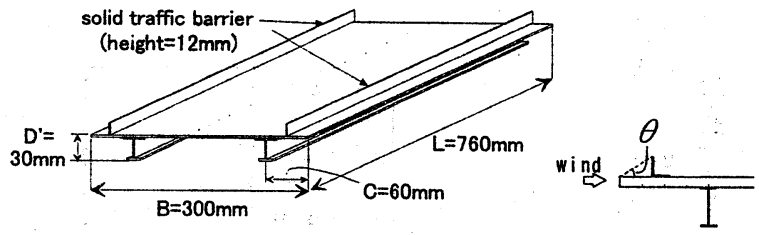

Fig. 1 Configuration of the experimental model

In this series of experiments, the location of the girders was set at $C / D^{\prime}=2.0$ with which the aerodynamic performance was found to be good in the previous study ${ }^{1)}$. Configurations without solid traffic barriers and with barriers of various locations $\theta$ (Fig. 1) were tested. 


\section{EXPERIMENTAL RESULTS}

\subsection{Response of $\pi$ section without solid barriers}

Heaving and torsional responses of the $\pi$ section without solid barriers are shown in Figs. 2 and 3. For the heaving responses, only vortex-induced vibration is observed. For the torsional responses, flutter is observed with positive angle of attack and the critical wind speed decreases with larger angle of attack. The occurrence of flutter is fatal for longspan bridges and therefore the countermeasures must be found.

\subsection{Response of $\pi$ section with solid barriers}

Figs. 4 and 5 show the response with solid traffic barriers with $\theta=30^{\circ}$. This configuration was found to be aerodynamically stable under $\alpha=0^{\circ 1)}$. Note that the representative length $D$ for reduced wind speed is defined as the total height $(=42 \mathrm{~mm}$ in 3.2 and $=30 \mathrm{~mm}$ in 3.1). Heaving response (Fig. 4) is more or less similar to that of the $\pi$ section without solid barriers showing only the vortex-induced vibration. For torsional response (Figs. 5), limited wind speed range response is observed with angles of attack other than $0^{\circ}$ and $-2^{\circ}$. The response amplitude is large for positive angles of attack. In contrast, the flutter observed in the positive angles of attack cases without solid barrier is suppressed, although limited amplitude response still remained

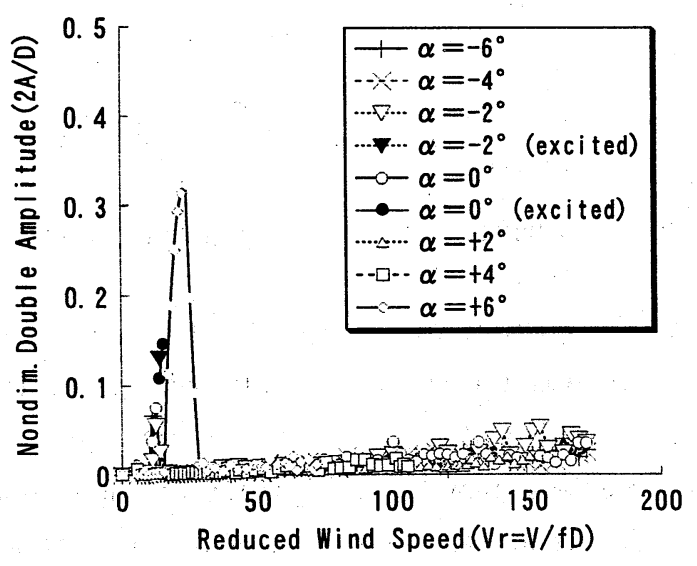

Fig. 2 Heaving response without solid barriers

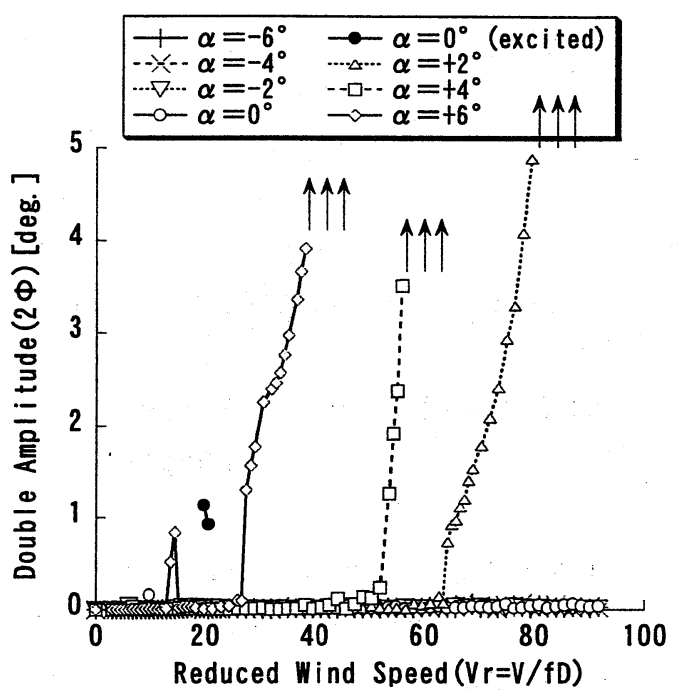

Fig. 3 Torsional response without solid barriers

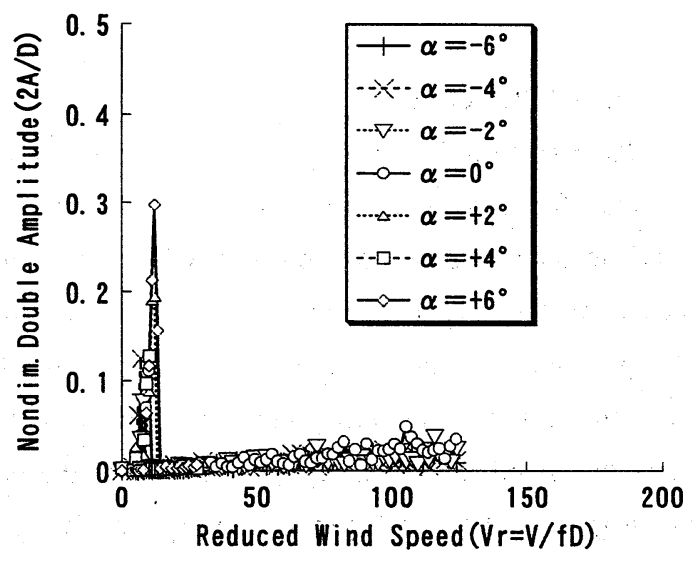

Fig. 4 Heaving response with barrier at $\theta=30^{\circ}$

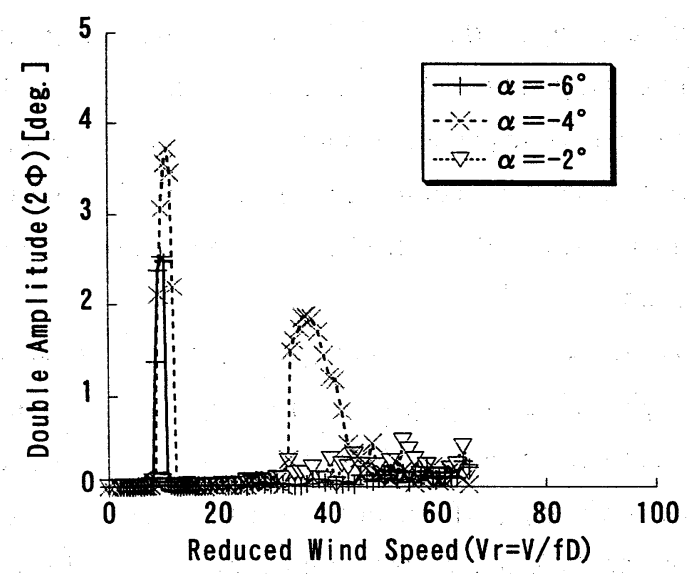

Fig. 5(a) Torsional response with barrier at $\theta=30^{\circ}$ (negative angle of attack cases) 
for $\alpha=4^{\circ}$ case.

The effects of the location of the solid barriers were further studied by changing $\theta$ to be $32^{\circ}$ and $34^{\circ}$, and torsional response results are shown in Figs. 6 and 7 . Their heaving responses are similar to $\theta=30^{\circ}$ case and thus omitted here. No significant torsional response is found in $\alpha=0^{\circ}$ and $2^{\circ}$ cases for both $\theta=$ $32^{\circ}$ and $34^{\circ}$ cases, whereas for $\theta=30^{\circ}$ case, no significant response is found for $\alpha=-2^{\circ}$ and $0^{\circ}$ cases. This may suggest the possibility of the dependence of the torsional response characteristics on the relative location of the barrier with respect to the angle of attack, $\theta-\alpha$, that is the angle of the line connecting the tips of the floor deck and the solid barrier with respect to the flow direction. Actually the torsional response of $\theta=30^{\circ}$ and $\alpha=2^{\circ}$ case is quite similar to that of $\theta=32^{\circ}$ and $\alpha=4^{\circ}$ case, and it seems to support this assumption. However, for example, the torsional response of $\theta=30^{\circ}$ and $\alpha=$ $-4^{\circ}$ case is not similar to that of $\theta=32^{\circ}$ and $\alpha=-2^{\circ}$ case, and thus the assumption seems to require further studies for clarification.

\subsection{Aerodynamic damping of responses}

In this study, the structural damping was set to be lower values than usually observed in actual bridges

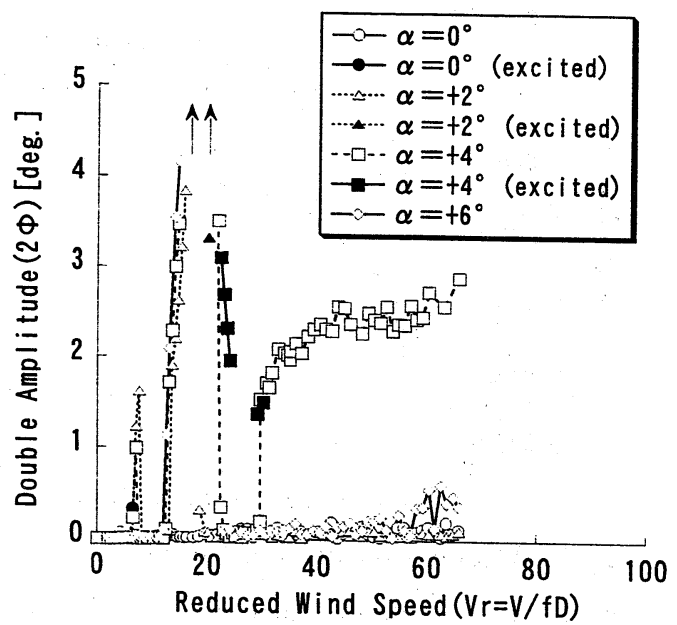

Fig. 5(b) Torsional response with barrier at $\theta=30^{\circ}$ ( $0^{\circ}$ and positive angle of attack cases)

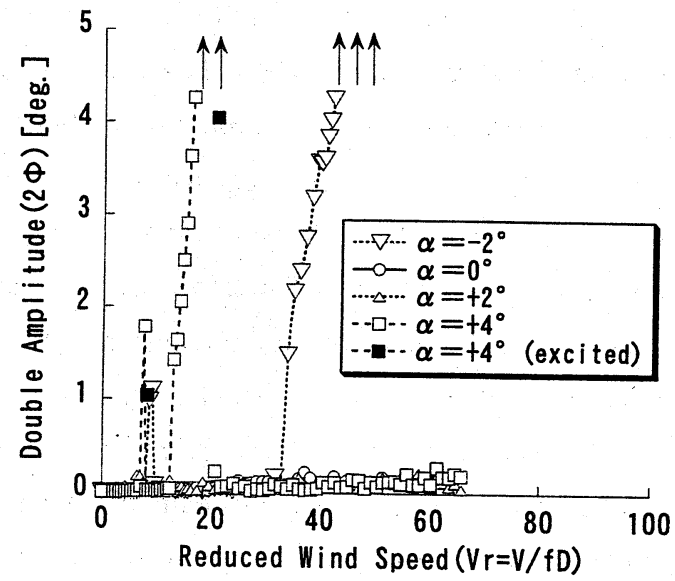

Fig. 6 Torsional response with barrier at $\theta=32^{\circ}$

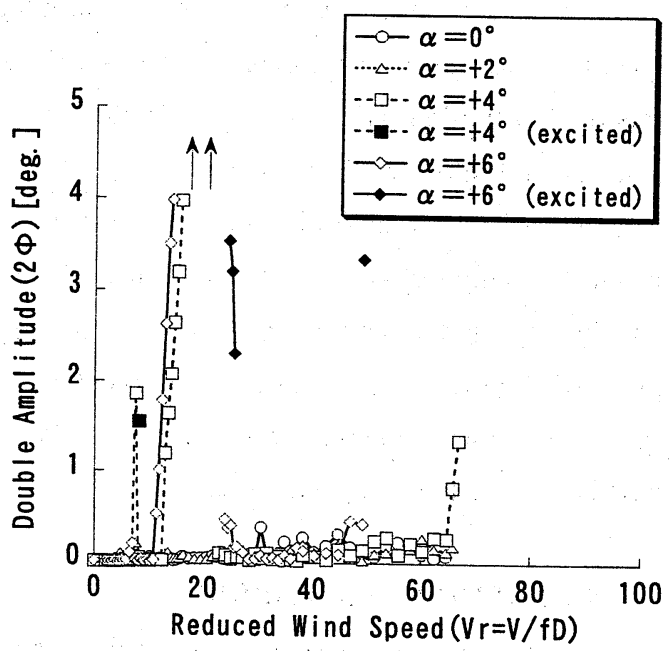

Fig. 7 Torsional response with barrier at $\theta=34^{\circ}$

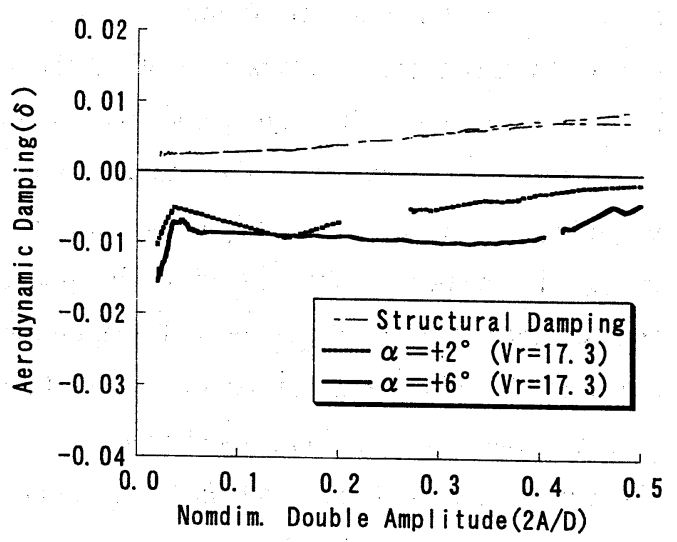

Fig. 8 Aerodynamic damping of heaving vortex-induced vibration $\left(\theta=30^{\circ}\right)$ 
in order to clarify the wind-induced response characteristics in more details. From the response characteristics described in the previous sections, the response with barrier at $\theta=30^{\circ}$ case seems to have better characteristics because no flutter-type response is observed. Therefore some typical examples of the aerodynamic damping for $\theta=30^{\circ}$ case are shown below to consider the occurrence possibility of the wind-induced vibration in actual bridges with higher structural damping than the experimental models.

The logarithmic aerodynamic damping at the response amplitude peak of heaving vortex-induced vibration is shown in Fig. 8. Also the damping at typical wind speed for limited wind speed range torsional vibration (Fig. 9) and for the torsional response at higher wind speed at $\alpha=4^{\circ}$ (Fig. 10) are shown. The magnitude of the aerodynamic negative damping is not large compared to the usually expected structural damping. Therefore, the proposed improved $\pi$ section is expected to have good enough aerodynamic performance that is stable under the tested wind speed range.

\section{CONCLUDING REMARKS}

Wind-induced response of improved $\pi$ sections was studied under various angles of attack. The response characteristics were found to be influenced largely by the angle of attack as well as the solid barrier location. Although some wind-induced responses were observed with the tested sections, the magnitude of the negative aerodynamic damping that causes the responses was found to be generally smaller than the usually expected magnitude of structural damping, thus the section can be thought as a probable choice for long-span bridges.

The characteristics of the aerodynamic forces and the flow pattern related to the responses were also studied, but they were omitted in this abstract due to the space limitation.

\section{Reference}

1) Y. Kubo, et al., Improvement of aeroelastic instability of shallow $\pi$ section, Volume of Abstracts, $4^{\text {th }}$ Int. Colloquium on Bluff Body Aerodynamics \& Applications, Sept. 2000, Bochum, pp. 451-454.

key words: wind-induced vibration, bridge aerodynamics, $\pi$ section bridge deck, wind tunnel experiment

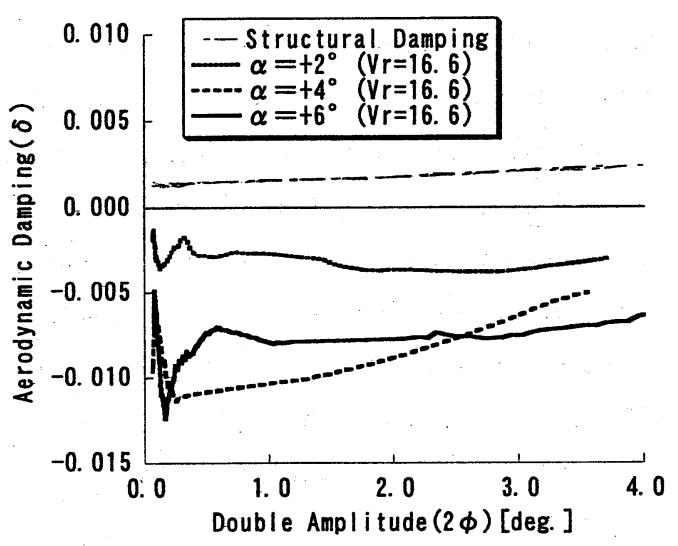

Fig. 9 Aerodynamic damping of limited wind speed range torsional vibration $\left(\theta=30^{\circ}\right)$

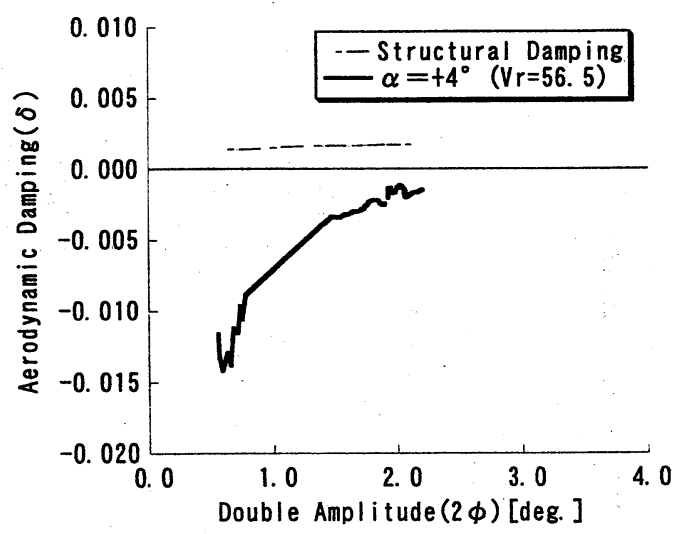

Fig. 10 Aerodynamic damping of limited amplitude torsional vibration at higher wind speed $\left(\theta=30^{\circ}\right)$ 


\title{
Torsional Flutter Mechanism of Two Edge Girders for Long Span Cable-Stayed Bridge
}

\author{
Masaru MATSUMOTO' ${ }^{1)}$, Yoshiyuki DAITO ${ }^{2)}$ and Kenji ARAKI ${ }^{1)}$
}

1) Department of Global Environment Engineering, Kyoto University, Kyoto 606-8501, Japan

2) Bridge \& Steel Structure Group, Sumitomo Heavy Industries, Ltd., Osaka 541-0041, Japan

\section{INTRODUCTION}

Recently, the bridge decks with two edge girders have been promoted for long-span cable-stayed bridges due to their structural and economical advantages. In the world scale, many cable-stayed bridges with two edge girders, such as Alex Frazer Bridge $^{1)}$, have been constructed until now. Two edge girders have been expected for the excitation of aerodynamic vibration, because their geometrical shapes resemble H-section ${ }^{2}$. However, the studies of those aerodynamic characteristics, such as the vortex-induced oscillation, the flutter instability and so on, have been superficial. In this study, the aerodynamic properties of some basic simplified 2dimensional (2D) models of two edge girders decks ${ }^{3}$ ) have been experimentally investigated. The fundamental data in smooth flow by changing the geometrical shapes, those location and the angle of attack of wind to bridge decks have been obtained.

\section{WIND TUNNEL TEST}

The wind tunnel, whose working section is $1.0 \mathrm{~m}$ width and $1.8 \mathrm{~m}$ height, was used. The tests were carried out mainly in smooth flow. The $2 \mathrm{D}$ models are the plate (cross-sectional width $B=300 \mathrm{~mm}$, deck depth $d^{\prime}=5 \mathrm{~mm}$, side ratio $B / d^{\prime}=60$ ) with some geometrical shapes of the edge girders. They are the I-girders $(B / D=10)$, box girders $(B / D=10)$ and circular pipe girders $(B / D=9.4)$, as shown in Figure 1 . Their models are scaled down by $1 / 100$. The girder

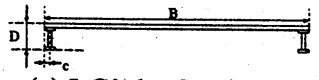

(a) I-Girder Section

$(\mathrm{B} / \mathrm{D}=10, \mathrm{c} / \mathrm{B}=0.013)$

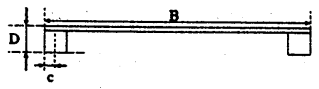

(c) Box-Girder Section

$(\mathrm{B} / \mathrm{D}=10, \mathrm{c} / \mathrm{B}=0.04)$

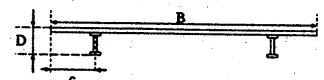

(b) I-Girder Section

$(\mathrm{B} / \mathrm{D}=10, \mathrm{c} / \mathrm{B}=0.167)$

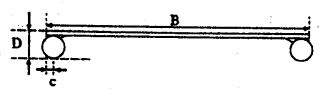

(d) Circular Pipe Girder Section $(B / D=9.4, c / B=0.03)$
Figure 1 Models with Various Geometrical Girders location (c) can be varied within $50 \mathrm{~mm}(\mathrm{c} / \mathrm{B}=0.167)$ from the deck's edge. The unsteady pressure was measured for two 2D models with I-girders $(B / D=10$, $\mathrm{c} / \mathrm{B}=0.013$ and 0.167 ) under forced torsional vibration in smooth flow. Equal space dots on the deck shown in Figure 2 are 20 pressure taps per each side

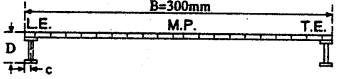

(a) I-Girder Section $(\mathrm{B} / \mathrm{D}=10, \mathrm{c} / \mathrm{B}=0.013)$

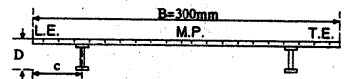

(b) I-Girder Section

$(\mathrm{B} / \mathrm{D}=10, \mathrm{c} / \mathrm{B}=0.167)$
Figure 2 Location of Pressure Taps of Two Edge Girders

\section{SHAPE EFFECTS ON AERODYNAMIC RESP- ONSE}

In this study, the free vibration tests have been conducted in order to clarify the fundamental aerodynamic response of two edge girders in heaving and torsional 1 degree of freedom (1 DOF) mode. In this study, torsional aerodynamic responses of two edge girders are mainly discussed. Scruton Numbers (abbreviated by Sc) were lower than the actual bridge dynamics, and center barriers and handrails are not attached on their sections. Moreover, their flow conditions are smooth flow, which is not equal to the similarity of a field wind flow condition. As a reference, $\mathrm{Vp}$, a field wind velocity for a certain long-span cable-stayed bridge with center span length of $600 \mathrm{~m}^{3}$, was indicated in following diagrams. Sc can be defined as follows;

$$
S c_{\eta}=\frac{2 m \delta_{\eta}}{\rho D^{2}} \quad \text { (1) } \quad S c_{\phi}=\frac{2 I \delta_{\phi}}{\rho D^{4}}
$$

where,

$m$ : mass per unit length $[\mathrm{kg} / \mathrm{m}], I$ : moment of inertia per unit length $[\mathrm{kg} \cdot \mathrm{m}], \delta_{\eta}, \delta_{\phi}$ :logarithmic damping, $\rho:$ air density $\left[\mathrm{kg} / \mathrm{m}^{3}\right], D$ :depth of girder [m] 


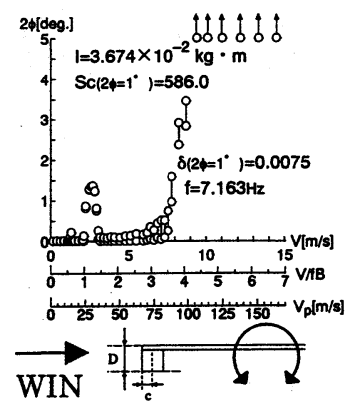

(a) Box Girder $(\mathrm{B} / \mathrm{D}=10)$

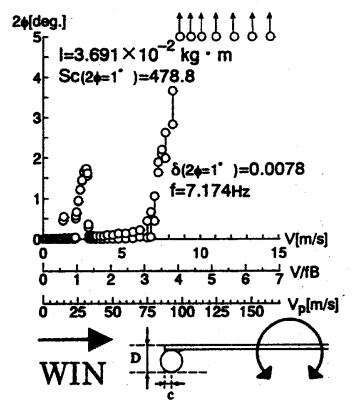

(b) Circular Pipe Girder $(B / D=9.4)$
Figure $3 \mathrm{~V}$-A diagrams of the sections with various girder shapes ( $\alpha=0^{\circ}$, Torsional 1DOF, in Smooth Flow)

The torsional response of two edge girders, as shown in Figure 3, shows that the onset-reduced velocities of the torsional flutter are also almost identical in independence of the geometrical girder shapes. Therefore, the girder shapes play a less important role for torsional flutter of two edge girders.

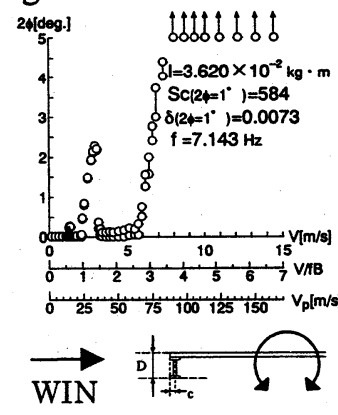

(a) I-Girder Section $(B / D=10, c / B=0.013)$

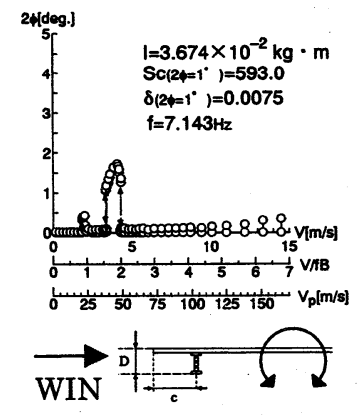

(b) I-Girder Section $(\mathrm{B} / \mathrm{D}=10, \mathrm{c} / \mathrm{B}=0.167)$
Figure $4 \mathrm{~V}$-A diagrams of I-girder sections with various girders locations $\left(B / D=10, \alpha=0^{\circ}\right.$, Torsional 1DOF)

Figure 4 shows the effect of girder locations on torsional response. When the girders are a little shifted toward deck center, torsional flutter is stabilized. That is to say, the girder location is very significant for aerodynamic characteristics of the torsional flutter. Moreover, it should be noted that the characteristics of torsional flutter instability are greatly sensitive for the change of the distance between two girders.

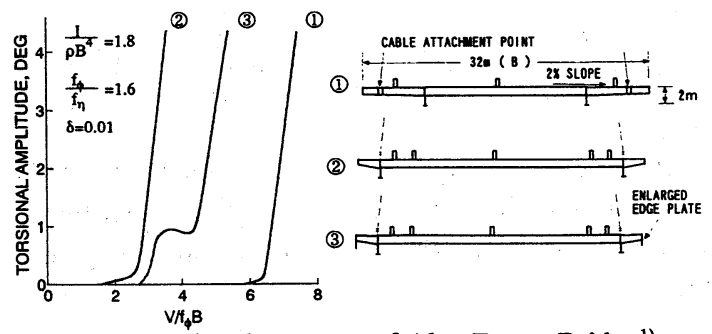

Figure 5 Torsional response of Alex Frazer Bridge ${ }^{1)}$
Figure 5 shows the torsional response for three various sections reported by P. Irwin ${ }^{1)}$. These concept were applied to the cable-stayed bridge with $465 \mathrm{~m}$ main span, Alex Frazer Bridge. These results show the fairly well agreement with that of this study from the point which onset of torsional flutter instability come to be lower, as the distance between two girders is larger, as shown in Figure 4.

\section{UNSTEADY AERODYNAMIC DERIVATIVES}

In order to clarify the flutter characteristics of those girder sections, the measurement of aerodynamic forces, such as the unsteady lift force (L) and unsteady pitching moment (M), were carried out in the state of heaving and torsional 1DOF forced vibration. The unsteady lift force (L) and unsteady pitching moment $(M)$ per unit length for heaving and torsional 2DOF system are expressed by eight unsteady aerodynamic derivatives proposed by Scanlan ${ }^{4}$, as following;

$$
\begin{aligned}
& L=\frac{1}{2} \rho(2 b) U^{2}\left\{k H_{1} \cdot \frac{\dot{\eta}}{U}+k H_{2} \frac{\cdot b \dot{\phi}}{U}+k^{2} H_{3}^{*} \phi+k^{2} H_{4} \frac{\eta}{b}\right\} \\
& M=\frac{1}{2} \rho\left(2 b^{2}\right) U^{2}\left\{k A_{1} \cdot \frac{\dot{\eta}}{U}+k A_{2} \cdot \frac{b \dot{\phi}}{U}+k^{2} A_{3} \cdot \dot{\phi}+k^{2} A_{4} \cdot \frac{\eta}{b}\right\}
\end{aligned}
$$

where

L:lift force per unit length [N/m]

M: pitching moment per unit length $[\mathrm{N} \cdot \mathrm{m} / \mathrm{m}]$

$\mathrm{H}_{\mathrm{i}}^{*}, \mathrm{~A}_{\mathrm{i}}^{*}(\mathrm{i}=1 \sim 4)$ : aerodynamic derivatives

$\eta$ : heaving displacement (downward positive) [m]

$\phi:$ torsional displacement (nose-up positive) [deg.]

$(\cdot)$ : time differential, $\mathrm{k}$ : reduced frequency $(\mathrm{b} \omega / \mathrm{U})$

$\mathrm{U}:$ wind velocity $[\mathrm{m} / \mathrm{s}], \rho:$ air density $\left[\mathrm{N} / \mathrm{m}^{3}\right]$

b: half chord length $[\mathrm{m}], \omega$ :circular frequency[Hz]

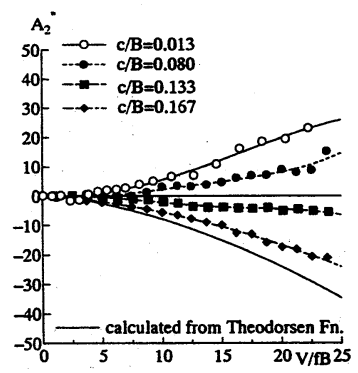

(a) $\alpha=0^{\circ}$

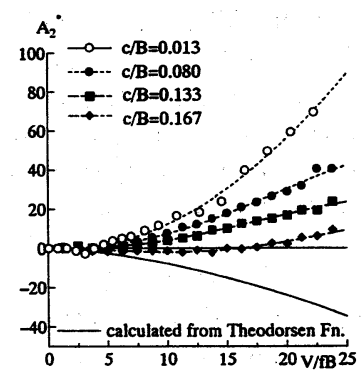

(b) $\alpha=+2^{\circ}$
Figure 6 Unsteady aerodynamic derivatives $A 2 *$ for the sections with various girder locations (I-girder sections)

When the distance of two girders is large, $A_{2}{ }^{*}$ increases to a positive value at very low reduced wind velocity at $\alpha=0^{\circ}$, which means the instabilization of torsional flutter. In contrast, when the distance is small, $\mathrm{A}_{2}^{*}$ remains negative even at higher reduced wind velocity, which indicates the stabilization of torsional flutter. Figure 6 shows that, as the distance 
between two girders is smaller, their flutter instability is more stabilized.

In order to investigate the effect of aerodynamic derivatives on flutter instability of two edge girders, Step-by-Step analysis also is carried out ${ }^{6}$. Figure 7 shows $\mathrm{V}-\delta_{\phi}$ diagram. In this analysis, logarithmic damping for the torsional branch, $\delta_{\phi}$, is shown as , obtained from summing up other four terms, $O$, $\square, \square, \diamond, \diamond . \delta_{\phi}$ is almost determined by their only two terms, $\bigcirc, \diamond$, as following:

$$
\begin{aligned}
\delta_{\phi} \fallingdotseq(1) \mathrm{A}_{2}^{*}-\delta_{3} & \\
& \text { where, } \delta_{3}=(1)(2) \mathrm{A}_{1}{ }^{*}\left|\mathrm{H}_{3}{ }^{*}\right| \cos \theta_{2}
\end{aligned}
$$

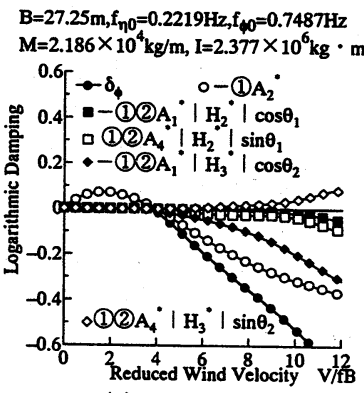

(a) $\mathrm{c} / \mathrm{B}=0.013$
$B=27.25 m, f_{n 0}=0.2219 \mathrm{~Hz}, f_{40}=0.7487 \mathrm{~Hz}$

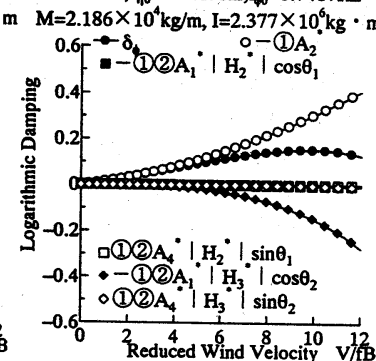

(b) $\mathrm{c} / \mathrm{B}=0.167$
Figure 7 Results of Step-by-Step analysis of I-girder section with $B / D=10$

$\mathrm{A}_{2}{ }^{*}$ plays an important role on the stability for coupled flutter or on the instability for torsional flutter. Figure 7 shows that, as the distance between two girders are large, the role of $\mathrm{A}_{2}{ }^{*}$ gradually change from that of instability for torsional flutter to that of stability for coupled flutter.

\section{EXPERIMENTAL CONSIDERATION OF TOR- SIONAL FLUTTER MECHANISM}

In order to clarify the cause of this instability, unsteady pressures on the side-surface of those girder sections were measured in the state of torsional 1DOF forced vibration in smooth flow.

The unsteady pressure is characterized by the amplitude $\tilde{c_{p}}$, and the phase difference to torsional response $\psi$, which is defined as the phase lag of negative pressure from the maximum pitching angle. Non-dimensionalized work (Wr), based on the amplitude $\tilde{c} p$, and the phase difference $\psi$, express the exciting source on side-surface.

Torsional flutter can be classified into three different types as follows; First one is "fluid memory", what is called, in which the phase difference of flow to torsional displacement plays a significant role on aerodynamic excitation. The second torsional flutter is initiated by vortex convection, related to one-shear layer instability, what is called; "low speed torsional flutter". The last one is "high speed torsional flutter", what is called, whose mechanism is fundamentally identical to that of coupled flutter ${ }^{6}$.

The aerodynamic characteristics of unsteady pressure of I-girder section with large distance between two girders have been described in the following. Figure 9 shows that the exciting source exists on downstream side of the side-surface at comparatively high reduced wind velocities, where the torsional flutter occurs. Their characteristics are almost identical with that of a rectangular cylinder which has same side-ratio $B / D=10^{7}$. Therefore, it is clear that this torsional flutter type is "low speed torsional flutter" one.

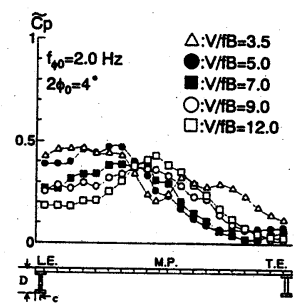

(a) $\tilde{C} p$ on the upper surface

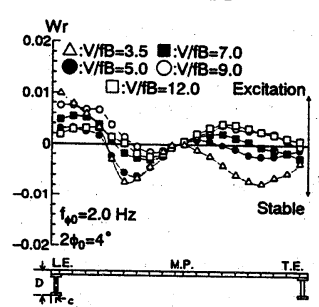

(c) Wr on the upper surface (d)Wr on the lower surface

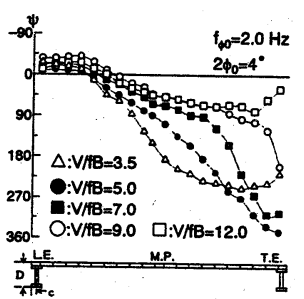

(b) $\psi$ on the upper surface

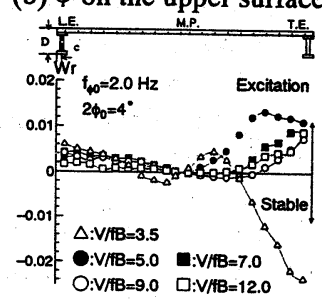

Figure 9 Diagrams of unsteady pressure on the upper surface of I-girder section with $\mathrm{B} / \mathrm{D}=10 \quad\left(\alpha=0^{\circ}\right.$, $\mathrm{c} / \mathrm{B}=0.013$ )

Figure 9-(d) shows the diagram of nondimensionalized work $(\mathrm{Wr})$ on the lower surface of I-girder section with $\mathrm{B} / \mathrm{D}=10$. The exciting sources exist on both upstream side and downstream side. At comparatively high-reduced wind velocity, where the torsional flutter occurs, the exciting source on downstream side has been emphasized.

In short, it is clear that flutter instability of two edge girders is closely related with the exciting source on the downstream side of upper and lower surface on the deck.

Non-dimensionalized total work of upper and lower surface is shown in Figure 10. The diagram shows that the exciting sources exist in the down-stream side at reduced wind velocity where torsional flutter occurs, and the stabilized forces are emphasized on the downstream side at that velocity where the torsional flutter is stabilized. 


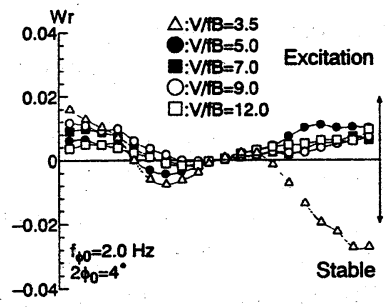

Figure 10 Non-dimensionalized total work diagrams of unsteady pressure of $\mathrm{I}$-girder section with $\mathrm{B} / \mathrm{D}=10$ ( $\alpha$ $=0^{\circ}, \mathrm{c} / \mathrm{B}=0.013$ )

The aerodynamic characteristics of unsteady pressure of I-girder section with small distance between two girders have been described in the following. This section shows the stabilization for the torsional flutter, as has been mentioned earlier.

The characteristics of phase difference of unsteady pressure, as shown in Figure 11, are particular and different from that of I-girder section with large distance between two girders. The phase differences gradually increase toward midpoint, then rapidly fall down and gradually decrease or increase. Those characteristics are similar to that of a slender rectangular cylinder $(B / D \geqq 15)^{7}$. Therefore, this torsional flutter type is "high speed torsional flutter" type, whose flow mechanism is identical to the coupled flutter type.

It is, in consequence, clear that the flutter stability of I-girder section with small distance between two girders is due to changing flow pattern from low speed torsional flutter type to coupled flutter type.

In other words, the small distance between two
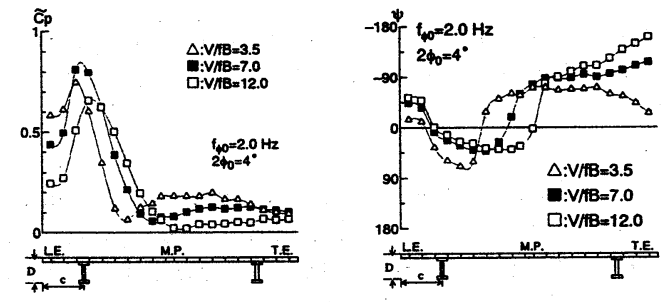

(a) $\tilde{c}_{p}$ on the upper surface (b) $\psi$ on the upper surface
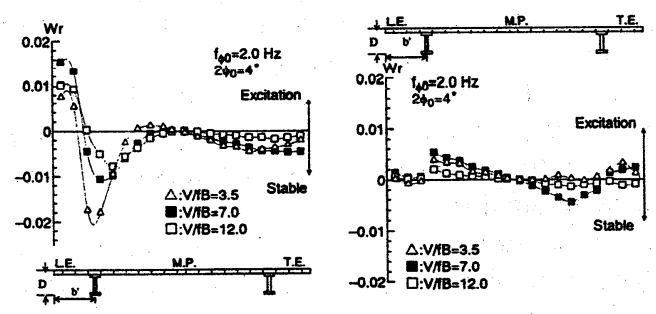

(c) Wr on the upper surface (d)Wr on the lower surface

Figure 11 Diagrams of unsteady pressure on the upper surface of I-girder section with $B / D=10 \quad\left(\alpha=0^{\circ}\right.$, $\mathrm{c} / \mathrm{B}=0.167$ ) girders changes the flow pattern on side-surface of two edge girders from that of low speed torsional flutter type to coupled flutter type

\section{CONCLUSIONS}

The obtained conclusions are summarized as follows:

1.The geometrical girder shapes and the location of girders sensitively affect on the characteristics of the vortex-induced oscillation and the flutter instability of two edge girders. Then, as the distance between two girders is smaller, their flutter instability are more stabilized.

2.It is clear that flutter instability of two edge girders is closely related with the exciting source on the downstream side of upper and lower surface on the deck. Moreover, the flutter stabilization of I-girder section with the small distance between two girders is due to changing flow pattern from low speed torsional flutter type to coupled flutter type.

3.The flutter stabilization of I-girder section with the small distance between two girders is due to changing flow pattern from low speed torsional flutter type to coupled flutter type.

\section{Reference}

1) Irwin, H.P. "Wind Tunnel Test of Long Span Bridges" Proc. IABSE Congress Vancouver 1984

2) M. Matsumoto, H. Shirato and S. Hirai, "Torsional Flutter Mechanism of 2D H-Shaped Cylinders and Effect of flow turbulence" Journal of WEIA 44-44 1992

3) M. Matsumoto, Y. Daito, "Aerodynamic Characteristics of two edge girders" Proc. of EASEC7th (The Seventh East Asia-Pacific Conference on Structural Engineering \& Construction) 1999

4) Scanlan, R.H., Belvay, J.G., Budlong, K.S; "Indicial Aerodynamic Functions for Bridge Decks," Journal of the Engineering Mechanics Division, Proceedings of ASCE. Vol. 100, EM4, August, 1974

5) M. Matsumoto, "Aerodynamic damping of prisms", IWEF (International Wind Engineering Forum) Meeting on Structural Damping, 1995

6) M. Matsumoto, Y. Daito and F. Yoshizumi, "Torsional Flutter of Bluff Bodies" Journal of Wind Engineering and Industrial Aerodynamics, 69-71, 1997.

7) M. Matsumoto, Y. Kobayashi and H. Hamasaki; "On Coupled Flutter for Fundamental Bluff Bodies," Proc. of 13th National Symposium on Wind Engineering 1994 (in Japanese)

key words: two edge girders, vortex induced oscillation, aerodynamic unsteady pressure, and torsional flutter 


\title{
Investigation on Aerodynamic and Structural Countermeasures for Cable-Stayed Bridge with 2-edge I-shaped Girder
}

\author{
Takuya MURAKAMI ${ }^{1)}$, Katsuaki TAKEDA ${ }^{1)}$, Michiaki TAKAO ${ }^{2)}$ and Rokusui YUI ${ }^{1)}$ \\ 1) Applied Technology Research Center, NKK, 1-1 Minamiwatarida-cho, Kawasaki-ku, Kawasaki 210-0855, \\ JAPAN \\ 2) Bridge design section, NKK, 2-1 Suehiro-cho, Tsurumi-ku, Yokohama, 230-8611, JAPAN
}

\section{INTRODUCTION}

Recently cable-stayed bridges with 2-edge I-shaped girder section are focused on in Japan from the economical points of view. These have been already adopted in the other part of world, especially in North America. In Japan, however, in order to have higher aerodynamic performance, box girder sections have been usually adopted so far. The aerodynamic disadvantages of 2-edge I-shaped girder section have to be improved.

The aerodynamic countermeasures have been conducted by the installation of additional members. For example, the overhanging deck and the edge plate are adopted in the Alex-Fraser bridge ${ }^{1)}$, the fairing in the Longs Creek Bridge ${ }^{2}$, the baffle plate in the Quincy Bridge $^{3)}$ and so on. However, in order to construct more economically, the practical use of the essential members in initial design stage is desirable. On the other hand, the structural countermeasures have been also conducted in order to improve flutter performance by increasing the total torsional rigidity of cable-stayed bridges. For example, high rigid A-type (or diamond-shaped) tower and the additional pier in the side span are adopted in the Yangpu Bridge ${ }^{4}$. However these aerodynamic effectiveness is not investigated in detail respectively.

This paper investigates aerodynamic and structural countermeasures for a cable-stayed bridge with a $400 \mathrm{~m}$ center span and a 2-edge I-shaped girder section. Firstly wind tunnel tests were conducted in order to confirm the performance of the new countermeasure where rectangular members, which are assumed to be essential attachments like maintenance passages or lifeline boxes, are protruded from the inside of the I-shaped main girders.
Next the structural countermeasures by increasing bridge rigidity were investigated in order to find effective countermeasures against flutter.

\section{AERODYNAMIC COUNTERMEASURE}

Spring supported tests were conducted in a $2 \mathrm{~m}(\mathrm{~B}) \times$ $3 \mathrm{~m}(\mathrm{H})$ test-section wind tunnel. This study was tested in smooth-flow only. 1:50 geometrical scale two section models are shown in Fig.1, whose prototype is 2-edge Ishaped girder section with $22 \mathrm{~m}$ width and $2 \mathrm{~m}$ height. Both have blocked central guard fence and $1.5 \mathrm{~m}$ height cross beam, and difference is found on the stringer whose height is $1.5 \mathrm{~m}$ in section A and $0.5 \mathrm{~m}$ in section $\mathrm{B}$. The properties of the section models are shown in Table 1. These are determined by properties of a cable-stayed bridge with a $400 \mathrm{~m}$ center span. A concept of new countermeasure in this study is shown in Fig.2. This shows that $1 \mathrm{~m}$ wide rectangular members are protruded from the inside of the I-shaped main girders in order to approach the good performance of corner cut-off sections. In this study, protruded depth $\mathrm{Pa}=20,50$ and $80 \mathrm{~cm}$ $(\mathrm{Pa} / \mathrm{D}=1 / 10,1 / 4$ and $2 / 5)$ are investigated.

Table 1 Properties of bridge section model

\begin{tabular}{|l|r|r|}
\hline Property & $\begin{array}{c}\text { Prototype } \\
\text { (assumed) }\end{array}$ & $\begin{array}{c}\text { Model } \\
\text { (Scale 1:50) }\end{array}$ \\
\hline Width & $22.0 \mathrm{~m}$ & $0.44 \mathrm{~m}$ \\
\hline Depth & $2.0 \mathrm{~m}$ & $0.04 \mathrm{~m}$ \\
\hline Mass & $25.23 \mathrm{t} / \mathrm{m}$ & $16.05 \mathrm{~kg} /$ Model \\
\hline Inertia & $1548 \mathrm{t} \cdot \mathrm{m}^{2} / \mathrm{m}$ & $0.394 \mathrm{~kg} \cdot \mathrm{m}^{2} / \mathrm{Model}$ \\
\hline Damping $(\delta)$ & - & 0.020 \\
\hline Bending freq. & $0.27 \mathrm{~Hz}$ & $2.10 \mathrm{~Hz}$ \\
\hline Torsional freq. & $0.54 \mathrm{~Hz}$ & $4.20 \mathrm{~Hz}$ \\
\hline
\end{tabular}




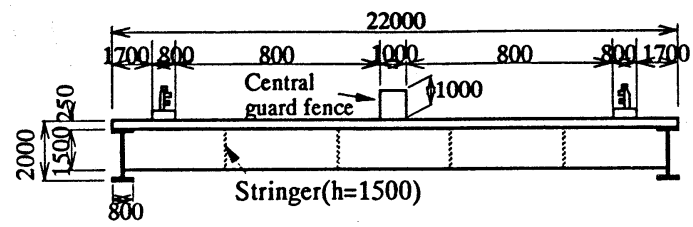

(a) Section A

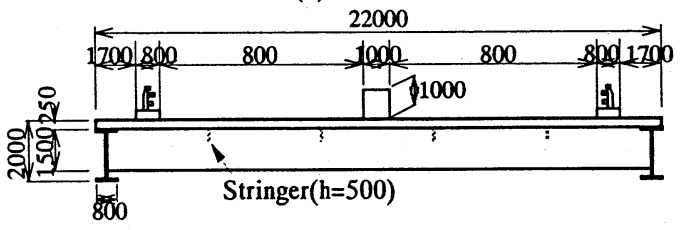

(b) Section B

unit:mm

Fig.1. Section model of 2-edge I-shaped girder

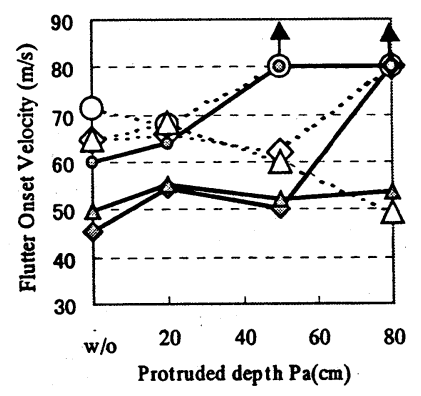

(a) Flutter

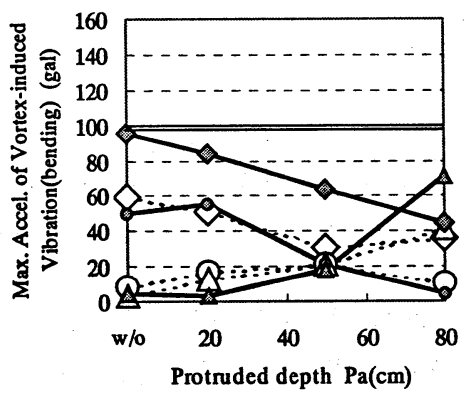

(b) Vertical vortex-induced vibration

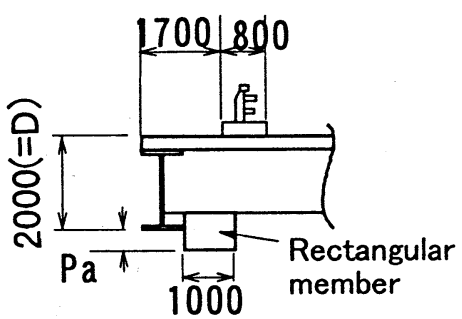

Fig.2. Concept of new countermeasure

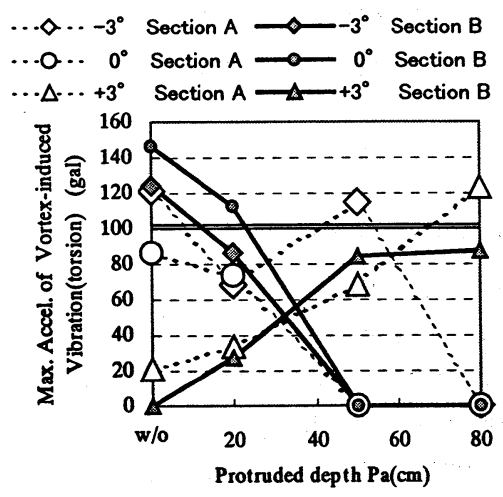

(c) Torsional vortex-induced vibration

Fig.3. Investigation on new countermeasure

The results are shown in Fig.3. Torsional flutter occurred in all cases and the amplitude of vortex-induced vibration was transformed into acceleration in order to compare a criterion for serviceability of $100 \mathrm{gal}$ written in Wind-proof Design Specifications for Highway Bridges?. In this figure the criterion is shown as double line. $\mathrm{Pa}=$ w/o means the case without rectangular members.

(1) Difference between section A and section $B$

Focusing on the cases of $\mathrm{Pa}=\mathrm{w} / \mathrm{o}$, flutter and vortexinduced vibration performance of section $A$ is better than that of section B. This shows that the higher stringer makes the flutter performance better like baffle plates. Section $B$ has lower flutter performance of onset velocity $45 \mathrm{~m} / \mathrm{s}$ at the angle of attack $\alpha=-3^{\circ}$ and $50 \mathrm{~m} / \mathrm{s}$ at $\alpha=0^{\circ}$. According to Wind-proof Design Specifications, over $60 \mathrm{~m} / \mathrm{s}$ flutter onset velocity is required on the standard condition for cable-stayed bridges in Japan that the level of girder position is $65 \mathrm{~m}$ and basic wind speed is $35 \mathrm{~m} / \mathrm{s}$. In addition, Maximum acceleration of torsional vortexinduced vibration exceeds $100 \mathrm{gal}$ at the angle of attack $\alpha=-3^{\circ}$ in both sections. Therefore some counter- measures against vortex-induced vibration have to be taken in section A and B, and some countermeasures against flutter may be taken in section $B$.

\section{(2) Effect of countermeasure}

In section $\mathrm{A}$, the increase of $\mathrm{Pa}$ makes aerodynamic performance worse at the angle of attack $\alpha=+3^{\circ}$. In the case of $\mathrm{Pa}=80 \mathrm{~cm}$ flutter onset velocity is about $50 \mathrm{~m} / \mathrm{s}$ and acceleration of torsional vortex-induced vibration reach about $120 \mathrm{gal}$. On the other hand, at the angle of attack $\alpha=-3^{\circ}$, torsional vortex-induced vibration performance is improved in the cases of $\mathrm{Pa}=20$ and $80 \mathrm{~cm}$. After all, in section $\mathrm{A}$, the case of $\mathrm{Pa}=20 \mathrm{~cm}$ has the best aerodynamic performance that flutter onset velocity is the same as the original section $\mathrm{A}(\mathrm{Pa}=\mathrm{w} / 0)$ and vortexinduced vibration is reduced to $70 \mathrm{gal}$. In section $\mathrm{B}$, at the angle of attack $\alpha=0^{\circ}$ and $-3^{\circ}$, the cases of $\mathrm{Pa}=50$ and $80 \mathrm{~cm}$ have better performance of vortex-induced vibration, whose acceleration is remarkably reduced. In addition, at $\alpha=+3^{\circ}$ the maximum acceleration of vortex-induced vibration does not exceed $100 \mathrm{gal}$ in all cases although the increase of $\mathrm{Pa}$ makes the acceleration 


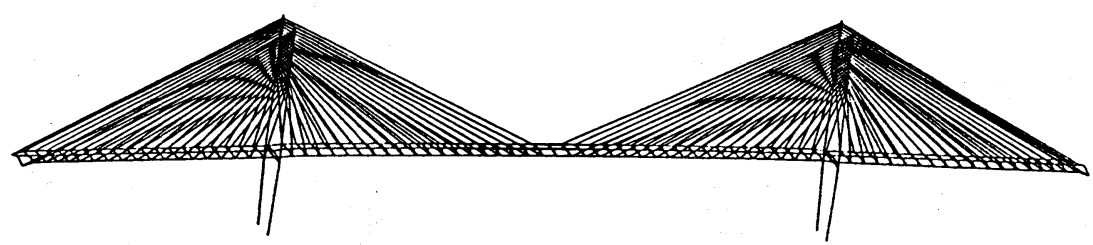

Fig.4. Eigenvalue analyses model $(180 \mathrm{~m}+400 \mathrm{~m}+180 \mathrm{~m})$

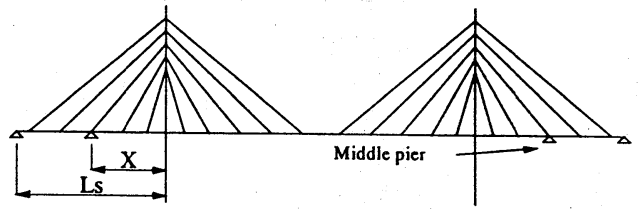

(a) Installation of middle Pier

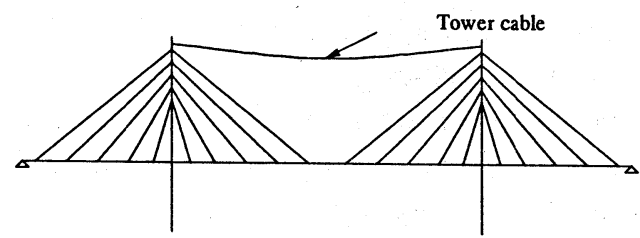

(b) Tower cable system

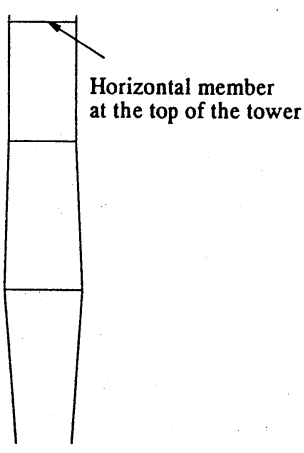

(c) Adding horizontal member

Fig.5 Concept of structural countermeasures

of vortex-induced vibration larger like section $\mathrm{A}$. However, flutter onset velocity is about $50 \mathrm{~m} / \mathrm{s}$ in all cases. After all, in section $\mathrm{B}$, the case of $\mathrm{Pa}=80 \mathrm{~cm}$ has the best aerodynamic performance that flutter performance is more than the original section $\mathrm{B}(\mathrm{Pa}=\mathrm{w} / 0)$ and vortexinduced vibration is reduced under 100gal. However, flutter onset velocity remain about $55 \mathrm{~m} / \mathrm{s}$, so another countermeasure against flutter may be necessary in a construction site.

In conclusion, the new countermeasure that protruded rectangular members installed at the inside of I-shaped main girders as assumed public attachments can be effective for vortex-induced vibration. However, the suitable protruded depth is different in the height of stringer.

\section{STRUCTURAL COUNTERMEASURE}

In order to investigate the effectiveness of structural countermeasures that the additional members are installed for the increase of total bridge rigidity, 2 D.O.F. flutter analyses were conducted. In this calculation, first the bending 1st mode and torsional 1st mode frequency are calculated by eigenvalue analysis and next flutter analyses were conducted by using eigenvalue analyses conclusions and measured flutter derivatives of section $\mathrm{A}$ without protruded rectangular members $(\mathrm{Pa}=\mathrm{w} / \mathrm{o})$. Eigenvalue analysis model is shown in Fig. 4 and its
Table 2 Properties of analytical model

\begin{tabular}{|c|c|c|c|}
\hline \multirow{3}{*}{\multicolumn{2}{|c|}{ Bridge Style }} & \multicolumn{2}{|c|}{ 3-span continuous cable-stayed bridge } \\
\hline & & \multirow{2}{*}{\begin{tabular}{|l|} 
Span \\
Stage of cables \\
\end{tabular}} & $180 m+400 m+180 m$ \\
\hline & & & 19 \\
\hline \multicolumn{3}{|c|}{ Girder-Tower connection } & floating style \\
\hline \multirow{8}{*}{ Girder } & \multirow{2}{*}{ Outline } & Shape & 2-edge I-shaped girder \\
\hline & & Width & $22 \mathrm{~m}$ \\
\hline & \multirow{2}{*}{ Mass } & Mass & $23 \mathrm{t} / \mathrm{m}$ \\
\hline & & Moment of Inetia & $2400 \mathrm{t} \cdot \mathrm{m}^{2}$ \\
\hline & \multirow{4}{*}{ Stiffness } & Area & $1.05 \mathrm{~m}^{2}$ \\
\hline & & Vertical & $0.8 \mathrm{~m}^{4}$ \\
\hline & & Horizontal & $160 \mathrm{~m}^{4}$ \\
\hline & & Bending-Torsional & $85 \mathrm{~m}^{6}$ \\
\hline \multirow{8}{*}{ Tower } & \multirow{2}{*}{ Outline } & Shape & H-shaped Steel \\
\hline & & Height & $144.5 \mathrm{~m}$ \\
\hline & \multirow{3}{*}{ Stiffness } & Out-Plane & $11 \sim 20 \mathrm{~m}^{4}$ \\
\hline & & In-Plane & $6 \sim 8 \mathrm{~m}^{4}$ \\
\hline & & Torsional & $15 \sim 21 \mathrm{~m}^{4}$ \\
\hline & \multirow{3}{*}{$\begin{array}{c}\text { Horizontal } \\
\text { Member }\end{array}$} & Out-Plane & $6 \mathrm{~m}^{4}(\mathrm{U}) \cdot 11 \mathrm{~m}^{4}(\mathrm{~L})^{41)}$ \\
\hline & & In-Plane & $5 m^{4}(U), 7 m^{4}(L)$ \\
\hline & & Torsional & $8 m^{4}(U), 15 m^{4}(L)$ \\
\hline
\end{tabular}

*1) U: Upper Member L:Lower Member

properties, which are different from Table 1 , are shown in Table 2. The analytical cases are shown in Fig.5. The additional piers in side span are installed in Fig.5(a), Tower cable system in Fig.5(b), and the additional horizontal members at the top of the tower in Fig.5(c). In the tower cable system, two cases were conducted in different sectional area of tower cable. The properties 
Table 3 Effectiveness of structural countermeasures

\begin{tabular}{|c|c|c|c|c|c|c|c|c|c|}
\hline \multicolumn{3}{|c|}{ Analytical Condition } & \multicolumn{3}{|c|}{ Frequency $(\mathrm{Hz})$} & \multirow{2}{*}{$\begin{array}{c}\text { Flutter } \\
\text { Onset } \\
\text { Velocity }\end{array}$} & \multicolumn{3}{|c|}{ the Rate of Increase } \\
\hline Girder & \multicolumn{2}{|c|}{ Countermeasure } & $\begin{array}{l}\text { Vertical } \\
\text { Sym. 1st }\end{array}$ & $\begin{array}{l}\text { Torsional } \\
\text { Sym. 1st }\end{array}$ & Ratio & & $\begin{array}{l}\text { Torsional } \\
\text { Sym. 1st }\end{array}$ & $\begin{array}{c}\text { Ratio of } \\
\text { Frequency }\end{array}$ & Flutter \\
\hline \multirow{7}{*}{$\begin{array}{l}2 \text {-edge } \\
\text { I-shaped }\end{array}$} & \multicolumn{2}{|c|}{ Nothing(Basic) } & $0.2711 \mathrm{~Hz}$ & $0.4605 \mathrm{~Hz}$ & 1.70 & $63 \mathrm{~m} / \mathrm{s}$ & 1.00 & 1.00 & 1.00 \\
\hline & \multirow{3}{*}{ Additional Pier } & $\mathrm{X}=\mathrm{Ls} / 4$ & $0.4041 \mathrm{~Hz}$ & $0.5246 \mathrm{~Hz}$ & 1.30 & $66 \mathrm{~m} / \mathrm{s}$ & 1.14 & 0.76 & 1.05 \\
\hline & & $\mathrm{X}=\mathrm{Ls} / 2$ & $0.4014 \mathrm{~Hz}$ & $0.5317 \mathrm{~Hz}$ & 1.32 & $66 \mathrm{~m} / \mathrm{s}$ & 1.15 & 0.78 & 1.05 \\
\hline & & $X=3 L s / 4$ & $0.3303 \mathrm{~Hz}$ & $0.4895 \mathrm{~Hz}$ & 1.48 & $64 \mathrm{~m} / \mathrm{s}$ & 1.06 & 0.87 & 1.02 \\
\hline & \multicolumn{2}{|c|}{ Adding Horizontal Member } & $0.2711 \mathrm{~Hz}$ & $0.5207 \mathrm{~Hz}$ & 1.92 & $73 \mathrm{~m} / \mathrm{s}$ & 1.13 & 1.13 & 1.16 \\
\hline & \multirow{2}{*}{ Tower Cable System } & Area 1 & $0.3230 \mathrm{~Hz}$ & $0.4934 \mathrm{~Hz}$ & 1.53 & $65 \mathrm{~m} / \mathrm{s}$ & 1.07 & 0.90 & 1.03 \\
\hline & & Area $10^{1}$ & $0.4825 \mathrm{~Hz}$ & $0.5226 \mathrm{~Hz}$ & 1.08 & $52 \mathrm{~m} / \mathrm{s}$ & 1.13 & 0.64 & 0.83 \\
\hline
\end{tabular}

(Remarks) 1) Area10 shows that the sectional area of tower cable is ten times as large as that of inclined cables.

of the additional horizontal member were assumed to be the same as the upper horizontal member.

The results are reviewed in Table 3. In effectiveness of countermeasure, all cases can increase the torsional frequency, but the installation of the additional middle piers and tower cable system can't increase flutter speed effectively. On the other hand, adding horizontal member at the top of the tower, which can increase only torsional frequency effectively, can increase the flutter speed at $16 \%$. Therefore adding horizontal members at the top of the tower is most effective in this study. This shows that frequency ratio would be a more important parameter than torsional frequency in cable-stayed bridges with 2 edge I-shaped girder like section $\mathrm{A}$.

In this application we have to pay attention to increasing the acceleration of vortex-induced vibration. For example, when its countermeasure is applied to the section $B$ with $P a=80 \mathrm{~cm}$, flutter onset velocity will be up to $65 \mathrm{~m} / \mathrm{s}$ from $55 \mathrm{~m} / \mathrm{s}$ in Fig. 3 (by using the same increase rate of $16 \%$ ). On the other hand, the acceleration of vortex-induced vibration, which is calculated by the increase rate $13 \%$ in this result, remains less than the criterion of $100 \mathrm{gal}$. Therefore, this can be effective with the combination of some girder section.

\section{CONCLUSION}

This paper investigates aerodynamic and structural countermeasures for cables-stayed bridges with 2-edge Ishaped girder section. The conclusions are as follows:

(1) Higher stringer in 2-edge I-shaped girder make flutter performance better in the girder section.

(2) The installation of protruded rectangular members at the inside of I-shaped main girders as assumed public attachments can be one of effective countermeasures for vortex-induced vibration.

(3) The suitable protruded depth is different in the height of stringer.

(4) The installation of horizontal members at the top of the tower is most effective for increasing flutter onset velocity in this study. Adding the middle pier in the side span and tower cable system can't increase flutter onset velocity effectively in spite of the increase of torsional frequency.

\section{Reference}

1) Irwin,P.A : "Wind Tunnel Tests of Long Span Bridge", Final Rep. $12^{\text {th }}$ Congress IABSE, p.689-696, 1984

2) Wardlaw, R.L: "Some Approaches for Improving the Aerodynamic Stability of Bridge Road Decks", Proc. Of Wind Effects on Building and Structures. (Tokyo), 1971

3) John M. KULICKI et al. : Design of the Cable-Stayed Mississippi River Bridge at Quincy, Illinois, Transportation Research Record 950, pp.34-50,

4) Lin Yuanpei, et al. : Design and Construction of Long Span Cable-stayed Bridges with Composite Girder in China, Bridge and Foundation, pp.25-34,1996.6

5) Wind-proof Design Specification for Highway Bridges, Japan Road Association 1991.7 (Japanese)

key words : aerodynamic countermeasure, cable-stayed bridge, 2-edge I-shaped girder section, spring supported tests 


\title{
FULL-SCALE MEASUREMENTS ON THE FRED HARTMAN BRIDGE
}

\author{
Ender Ozkan, Joseph Main and Nicholas P. Jones \\ Department of Civil Engineering, The Johns Hopkins University \\ 3400 N. Charles Street, Baltimore, MD 21218 USA
}

\section{INTRODUCTION}

Following the well-known collapse of Tacoma Narrows Bridge in 1940, many researchers have attempted to identify the mechanisms associated with wind-induced vibrations of long-span bridges. While very sophisticated response prediction techniques have been devised over the years in the field of bridge aerodynamics, relatively few long-term studies have been carried out in prototype structures to evaluate the performance of these techniques. The type of comprehensive instrumentation system needed as well as long-term commitments to data analysis and reporting pose great challenges associated with such long-term projects. However, it is evident that the data obtained from these measurements under various meteorological conditions can provide important insights about the principal mechanisms of bridge aerodynamics as well as helping to improve the current analytical prediction techniques.

Motivated in part by this idea, long-term full-scale field measurements are being performed on the Fred Hartman Bridge near Houston, Texas. Among the various objectives of this project are efforts to identify the modal characteristics, such as natural frequencies and mode shapes of the structure, develop estimates of modal damping values and examine the performance of the structure under a range of meteorological conditions. This paper summarizes findings from the efforts described above, as well as describing examples of interesting features of individual vibration events.

\section{DESCRIPTION OF THE BRIDGE AND IN- STRUMENTATION}

Opened to traffic in 1995, the Fred Hartman Bridge (Fig. 1) connects the industrial towns of La Porte and Baytown, Texas. It is a twin deck cable-stayed bridge with a center span of $380 \mathrm{~m}$ and two side spans of $147 \mathrm{~m}$ The decks are composed of precast concrete slabs on steel girders and are $24 \mathrm{~m}$ wide each, carrying four lanes of traffic. The decks are carried by a total of 192 cables, arranged in four inclined planes and connected to the deck at $15 \mathrm{~m}$ intervals.

One of the biggest challenges related with such long-term monitoring projects is the need for robust, comprehensive instrumentation systems. The instruments are prone to extreme climate conditions, such as strong winds, rain, thunderstorms and temperature changes throughout the course of the multiyear test program. Therefore, it is vital to have an instrumentation system that maintains a high level of durability and accuracy.

The basic instrumentation system used in this project consists of the following components, although elements have changed and continue to change on a regular basis:

- 2 three-axis anemometers at the deck level

- Propeller-vane anemometer at the south tower top

- 19 two-axis accelerometers installed on stay cables ( $\pm 4 \mathrm{~g}$ range)

- 8 displacement transducers installed on stays

- 8 strain gauges and 2 load cells

- 5 accelerometers, 4 one-axis and a two axis, installed on the bridge deck ( $\pm 4 \mathrm{~g}$ range) 
- 2 rain gauges $(0.25 \mathrm{~mm}$. resolution)

- Temperature probe and barometer

- 4-pole Bessel filters set to $10 \mathrm{~Hz}$ (sampling frequency $40 \mathrm{~Hz}$ )

- Windows-based Pentium PC with data acquisition and remote communication software.

Fig. 1 shows the locations of some of the instrumentation. All of the instruments are continuously monitored using a remotely interrogated self-triggering system which records trigger files on the basis of exceedance of threshold motion and wind levels. The recorded data files contain 5-minute trigger runs that are sampled at $40 \mathrm{~Hz}$ and are stored on highcapacity removable disks for further processing.

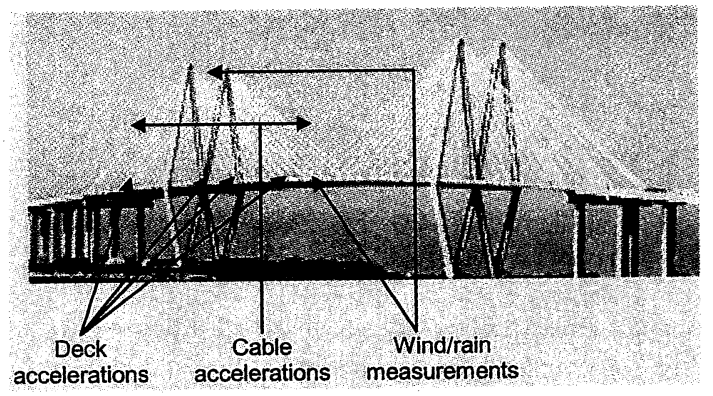

Figure 1. Instrument locations.

\section{DECK VIBRATION MEASUREMENTS AND DATA ANALYSIS}

Another significant challenge related with long-term monitoring projects is the process of analyzing large quantities of data. More than 8000 trigger files have been recorded during the three years of the test program and more are continuously being collected. Analyzing such a large number of data files demands extensive use of automated procedures. However, the use of such procedures must be carefully controlled to ensure that flawed or questionable data are not included in the study. The data analysis techniques used in this project have been automated to the greatest extent considered prudent, with careful consideration to maintaining the integrity and accuracy of the data and not missing important features of individual records.

The recorded files are initially processed to determine the general features of the raw data. These features include the mean, standard deviation and other higher moments of the data as well as one-minute average wind speeds/directions, accelerations and displacements, all of which are automatically added to a database. The database provides for easy analysis and correlation of these statistical quantities. It is also possible to readily interrogate the data using queries created and stored in the database.

Modal frequencies and mode shapes have been found and these values have been compared with values obtained from finite element (FE) analysis. Preliminary results of this comparison have been presented previously (Ozkan et al. 2001). Table 1 shows the comparison of measured modal frequencies with those obtained from a FE analysis for the first 20 modes. In general, good agreement between the two data sets is observed. Similarly, the mode shapes have been found for the first 20 modes, showing reasonable agreement with those calculated from the FE analysis (Ozkan et al. 2001).

To investigate the wind-vibration characteristics of the bridge deck, plots of root mean square (RMS) acceleration of the deck versus wind speed have been made (Fig. 2-a). A general trend of increasing RMS acceleration with wind speed can be observed from this figure. However, it is interesting to note two distinct patterns of acceleration amplitude. Measurements were taken over periods when the stay cables were damped and undamped during the three-year test program. Using this information, Fig. 2(a) can be divided into Fig. 2(b) and 2(c) corresponding to periods when the cables were damped and undamped, respectively. Two very distinct acceleration patterns can be seen from these figures, clearly suggesting the possibility of different interactions between the deck and the cable motions.

The characteristic appearance of Fig. 2(c) is believed to be primarily due to excitation of the deck caused by oscillation of the adjacent stay during wind-rain and other high-amplitude-inducing events (e.g., Main and Jones 1999). Fig. 2(b) is more representative of global motion of the deck, although to investigate this behavior further, specific records of interest must be analyzed in detail. An example is given in Fig. 3. This record was obtained during the passage of a storm and contains the highest measured wind speeds. For this specific record, Fig. 3(a) and (b) show the time-histories and power spectral densities (PSD's) of vertical deck acceleration at midspan and in plane acceleration of the adjacent stay cable AS24 (length $198 \mathrm{~m}$.; natural frequency approximately $0.59 \mathrm{~Hz}$ ) respectively. Fig. 3(c) shows the wind speed at tower level. All of the deck accelerations measured during this event show a dominant frequency of vibration at approximately $0.58 \mathrm{~Hz}$. It is interesting to note that this frequency corresponds to the third symmetric vertical mode of the deck (given as approximately $0.56 \mathrm{~Hz}$ in Table-1), and is also close to the first mode of the stay cable AS24. 


\begin{tabular}{|c|c|c|c|c|c|}
\hline Mode & $\begin{array}{c}\text { Long-Term } \\
\text { Measured } \\
\text { Frequency }(\mathrm{Hz})\end{array}$ & $\begin{array}{c}\text { FEM } \\
\text { Frequency }(\mathrm{Hz})\end{array}$ & $\begin{array}{l}\text { Percentage } \\
\text { Difference }\end{array}$ & $\begin{array}{c}\text { Phasing } \\
\text { ( } 1 \text { :in-phase } \\
\text { O: Out-of-phase) }\end{array}$ & $\begin{array}{c}\text { Description } \\
\text { of the Mode (FE) }\end{array}$ \\
\hline 1 & 0.290 & 0.286 & 1.4 & 1 & Vertical \\
\hline 2 & 0.299 & 0.291 & 2.8 & 0 & Vertical \\
\hline 3 & 0.375 & 0.366 & 2.5 & 1 & Vertical \\
\hline 4 & - & 0.377 & - & 0 & Vertical \\
\hline 5 & 0.432 & 0.410 & 5.4 & O & Lateral \\
\hline 6 & $\therefore$ & 0.426 & - & 1 & Lateral \\
\hline 7 & 0.564 & 0.556 & 1.4 & 1 & Vertical \\
\hline 8 & $\therefore$ & 0.562 & - & 0 & Vertical \\
\hline 9 & - & 0.612 & $\therefore$ & 0 & Torsional \\
\hline 10 & 0.586 & 0.625 & 6.2 & 1 & Vertical \\
\hline 11 & $\therefore$ & 0.634 & - & 0 & Vertical \\
\hline 12 & 0.665 & 0.658 & 1.1 & 1 & Vertical \\
\hline 13 & - & 0.659 & - & - & Torsional-Lateral \\
\hline 14 & 0.683 & 0.662 & 3.2 & $=$ & Torsional-Bending \\
\hline 15 & 0.714 & 0.735 & 2.9 & 1 & Vertical \\
\hline 16 & - & 0.736 & - & 0 & Vertical \\
\hline 17 & $\because$ & 0.756 & - & 1 & Torsional \\
\hline 18 & 0.784 & 0.757 & 3.6 & 0 & Vertical \\
\hline 19 & - & 0.817 & - & 1 & Torsional \\
\hline 20 & 0.924 & 0.856 & 7.9 & $\mathrm{~T}$ & Vertical \\
\hline
\end{tabular}

Table 1: Comparison of measured deck modes with FE analysis
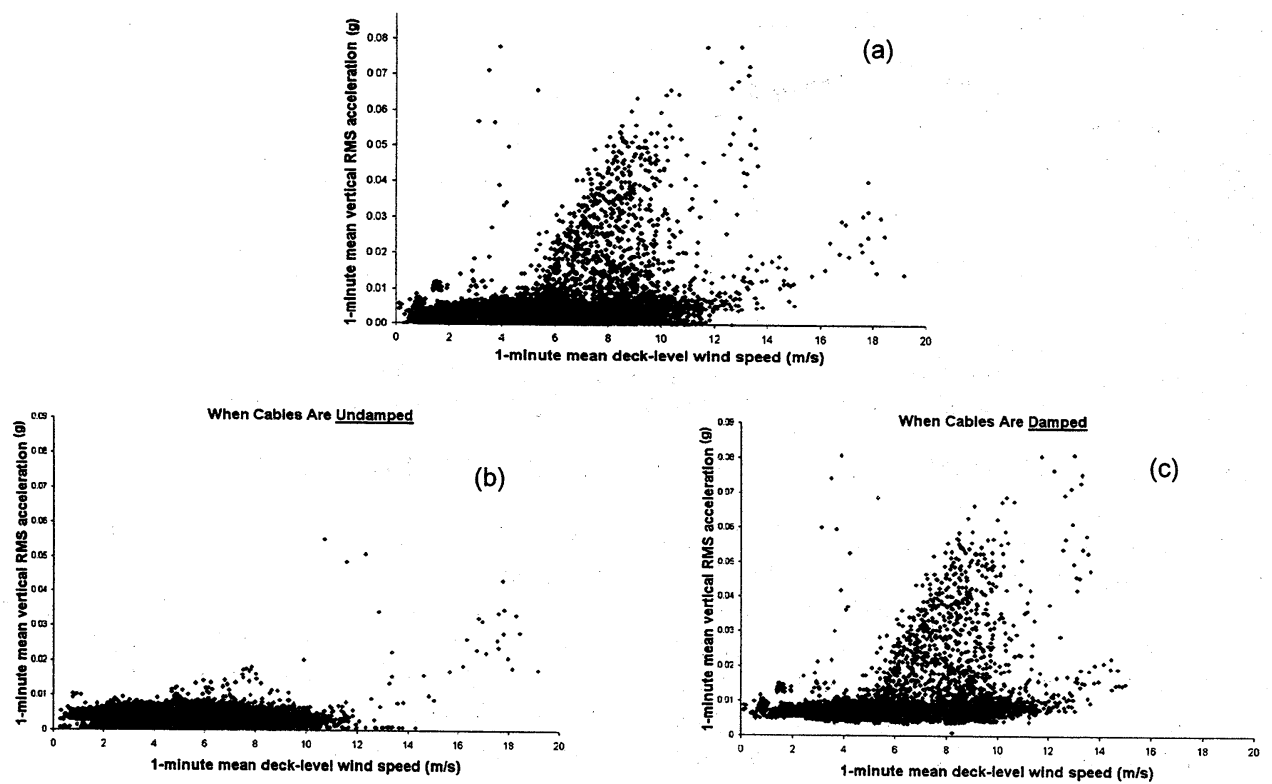

Figure 2. RMS deck acceleration vs. wind speed a) all, b) cables damped and c) cables undamped.

This is an interesting and important observation since the first-mode vibrations of a cable at this level of acceleration are generally associated with large displacements. In fact, by integrating the acceleration time-history, a displacement amplitude of approximately one meter (peak to peak) was estimated.

Furthermore, by observing the time-histories it can be seen that the significant vibrations are initially observed at the deck, which are immediately fol- lowed by large vibrations at the cable. This observation, as well as the similarity of modal frequencies suggests that the deck is driving the cable to vibrate with large amplitude in its fundamental mode. Vortex-induced vibration of the deck is thought to be the driving mechanism for this motion. Further studies are continuing to better understand the underlying mechanisms involved in this behavior and its consequences, and will be reported in future papers. 


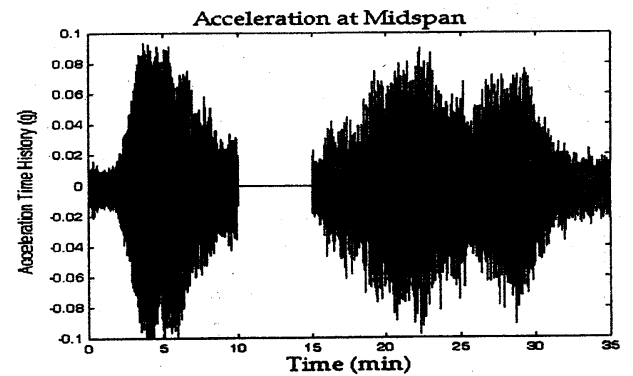

(a)
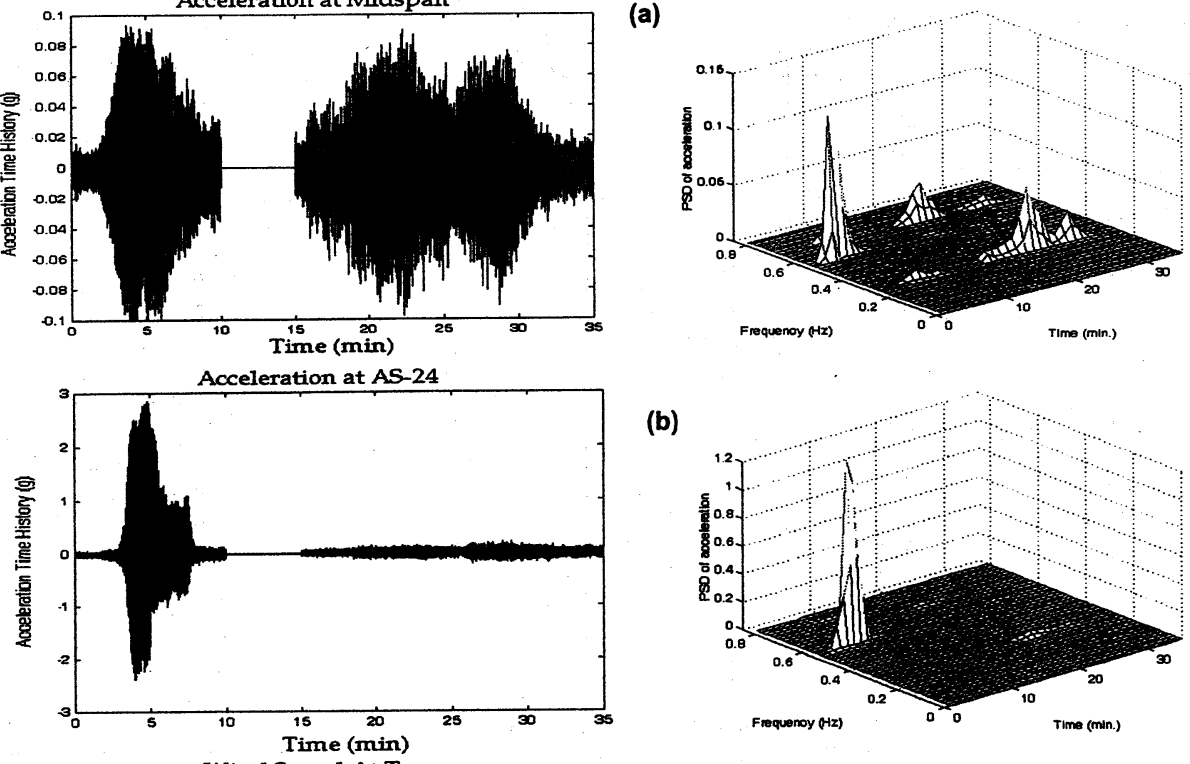

(b)
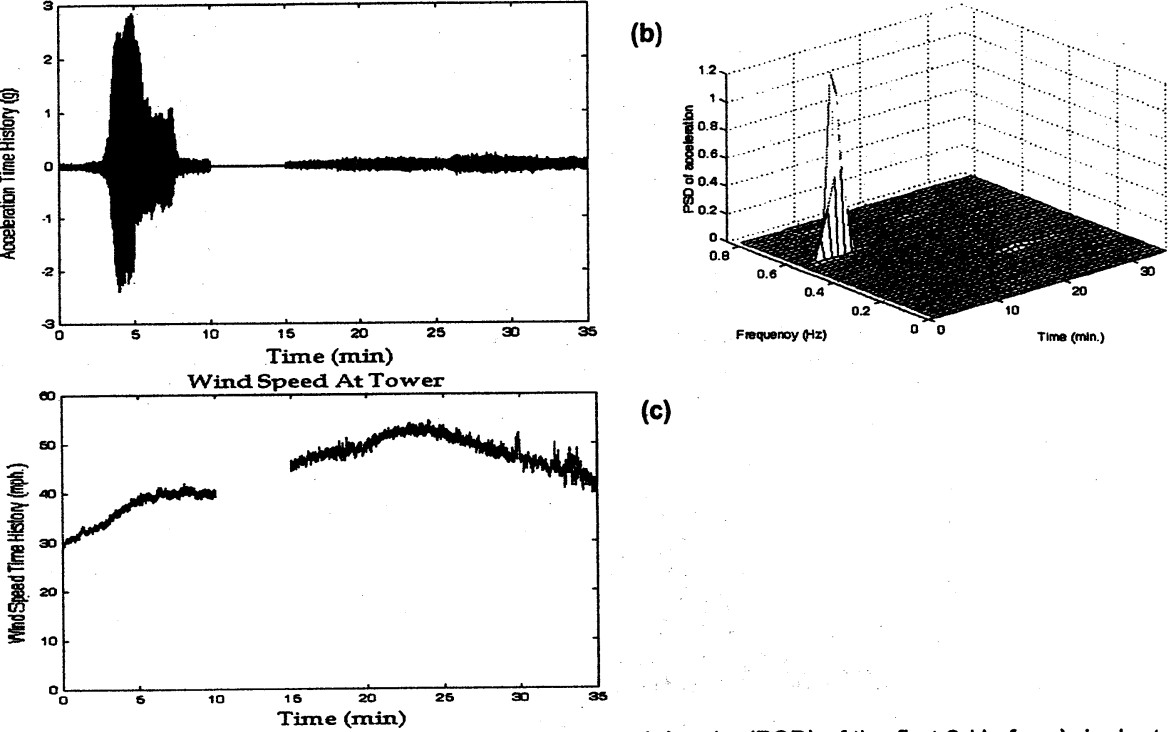

(c)

Figure 3. Plots of time history and power spectral density (PSD) of the first 2-Hz for a) deck at midspan (vertical dir.), b) cable at AS24 (in-plane dir.) and c) deck level wind speed.

\section{CONCLUDING REMARKS}

The preceding paper presents an overview of longterm efforts to monitor a cable-stayed bridge for a variety of purposes, including understanding the modal characteristics and wind-induced responses under ambient wind conditions. Using data files collected during various meteorological conditions, natural frequencies and mode shapes of the deck were found using an automated data analysis procedure. The measured modal frequencies and mode shapes observed to agree with the predicted values found from a finite element analysis.

While automated data analysis procedures are clearly necessary for such large volumes of data, care must be taken not to miss or obscure important phenomena or characteristics through this approach. The interaction observed between the deck and a stay is a good example of a situation where careful interpretation of the data is required to fully understand the relevant underlying mechanics.

\section{ACKNOWLEDGEMENTS}

The authors would like to acknowledge Texas Department of Transportation, the US National Science Foundation, the US Federal Highway Administration, the US Department of Defense (NDSEG Fellowship) and the Department of Civil Engineering at Johns Hopkins University for the support of various components of this work.

\section{REFERENCES}

1) Main, J.A. and Jones, N.P., Full-Scale Measurements of Cable Vibration, Proc. 10th International Conference on Wind Engineering, pp. 963$970,1999$.

2) Ozkan, E., Main, J.A. and Jones, N.P., Longterm Measurements on a Cable Stayed Bridge, Proceedings of IMAC-XIX Congress, February 2001.

key words: cable-stayed bridge, full-scale measurements 


\title{
Measurement and Mitigation of Stay Cable Vibration
}

\author{
Joseph Main ${ }^{1)}$ and Nicholas P. Jones ${ }^{1)}$ \\ 1) Dept. of Civil Eng., Johns Hopkins University, 3400 N. Charles St., Baltimore, MD 21218, USA
}

\section{INTRODUCTION}

The problem of large-amplitude stay vibrations on cable-stayed bridges is now quite well known, and vibration mitigation has become a significant concern to engineers in the design of new bridges and for retrofit of existing bridges. Stay cables have very low levels of inherent mechanical damping, rendering them susceptible to multiple types of excitation. To suppress the problematic vibrations, dampers are often attached to stay cables near the anchorages to supplement the inherent damping, and the effectiveness of attached dampers in mitigating stay vibrations has been demonstrated. Long-term measurements by the authors on three cable-stayed bridges in the United States indicate that the problematic large-amplitude rain-wind vibration events were largely eliminated on monitored stays after the installation of dampers (Main and Jones 1999). In order to design effective and economical dampers for stay-cable vibration mitigation, it is important to have both a reliable characterization of the vibrations occurring in the field and a thorough understanding of the mechanics of a taut cable with an attached damper. This abstract summarizes recent investigations by the authors aimed at improving the current understanding in these complementary areas.

\section{CHARACTERIZATION OF VIBRATIONS}

This abstract presents cable vibration data from a long-term field-measurement program at the Fred Hartman Bridge, a twin-deck cable-stayed bridge over the Houston Ship Channel in Texas (Fig. 1). At the time of writing, the Hartman instrumentation system (Main and Jones 1999) has been installed for more than three years, collecting more than 8000 five-minute records of varying acceleration amplitude and meteorological conditions; approximately 2700 records were generated during the first year of monitoring, before the installation of a temporary restraining system. Several distinct types of vibrations have been identified in the measured data, including rain-wind induced vibrations, vortex- induced vibrations, and deck-induced vibrations. Special attention has been devoted to the analysis of rain-wind induced vibrations because of their large amplitudes and relatively frequent occurrence, and this abstract focuses on data from records of largeamplitude rain-wind-induced vibration.

Accelerometers were used to record the cable vibrations; however, the displacement response is often of more direct interest than the acceleration response, which exaggerates higher mode contributions. Displacement time histories were generated by filtering and numerically integrating selected acceleration records, and statistics were then computed from the resulting displacement records to characterize the vibration response. Currently, 296 records of largeamplitude vibration have been analyzed using these techniques; analysis is ongoing and the observations presented herein are preliminary. More details about the procedure and results of this analysis can be found in (Main et al. 2001).

The dominant mode of vibration was identified from a power spectral density estimate of the displacement signal as the mode with the largest root-meansquare (RMS) response. Fig. 2 shows a histogram of the dominant mode for all records from various stays. The number of the dominant mode ranges from 1 to 4 , with most of the responses occurring in

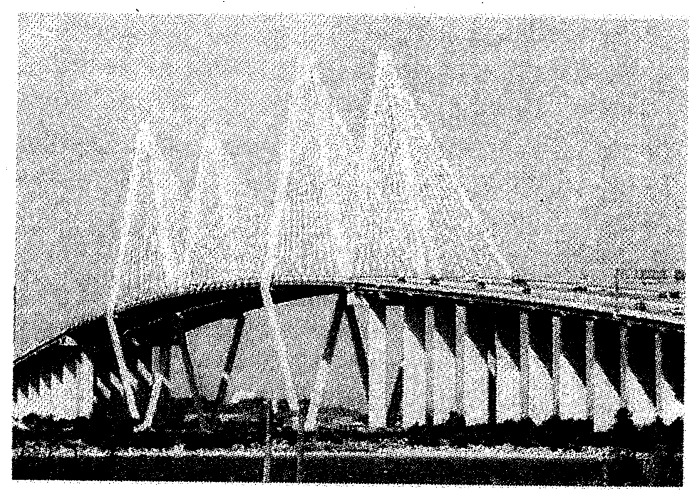

Figure 1. Fred Hartman Cable-Stayed Bridge 
modes 2 and 3. It is important to note that because the natural frequencies are different for different stays, the frequency of oscillation may be significantly different even when the mode number is the same. Fig. 3 shows a histogram of frequency of the dominant mode, and from this figure it is evident that the responses are distributed over a fairly wide range of frequencies. Most of the responses have frequencies between 1 and $3 \mathrm{~Hz}$. It is also important to evaluate whether the vibration responses are dominated by a single mode or if multiple modes participate in the responses. To allow for a quantitative assessment, it is helpful to use a parameter called the Modal Contribution Index (MCI; Jones and Porterfield 1997):

$$
M C I=\frac{A_{\text {dom }, R M S}}{\sqrt{\sum_{i} A_{i, R M S}^{2}}}
$$

Herein, the summation is taken over the five modes with the highest RMS amplitudes. The MCI approaches unity as the response approaches a purely single-mode response, and the MCI decreases as the participation of other modes becomes more significant, approaching 0.45 when the five highest modes have equal amplitude. Fig. 4 shows a histogram of $\mathrm{MCI}$; it is evident in this figure that the majority of the responses are nearly single-mode events.

An important characteristic of rain-wind induced vibrations is the rate of increase of vibration amplitude under the action of the excitation mechanism.

If the onset of self-excited vibrations is modeled by negative damping, the oscillation amplitude increases exponentially. The net damping ratio in mode $i$ is the sum of the mechanical damping ratio and the aerodynamic damping ratio in that mode:

$$
\zeta_{i, \text { et }}=\zeta_{i, \text { mech }}+\zeta_{i, \text { aer }}
$$

The mechanical damping ratio is always positive, but the aerodynamic contribution may be negative, potentially resulting in exponentially increasing oscillation amplitudes. Numerous stay vibration records have been captured in which the oscillation amplitude increases dramatically in a short period of time, and the increase in amplitude was indeed observed to be very nearly exponential for low amplitudes. The estimated values of net negative aerodynamic damping ratio estimated from 41 records ranged from about $0.07 \%$ to almost $0.5 \%$. These estimated values indicate the amount of additional damping that must be provided by supplemental damping devices in order to suppress the rain-wind induced vibrations. The computed values of net damping ratio can be normalized by computing the associated Scruton number:

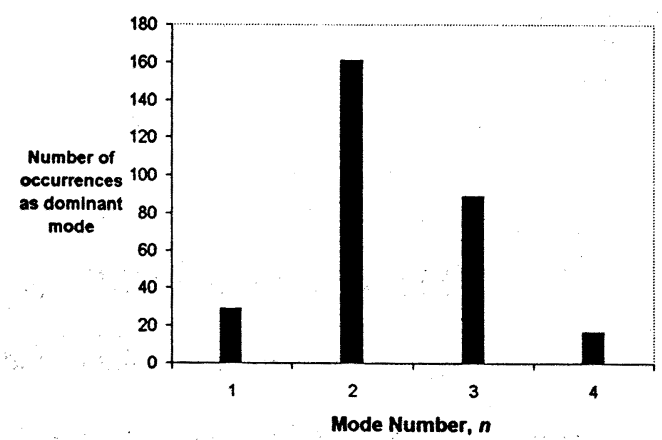

Figure 2. Histogram of dominant mode.

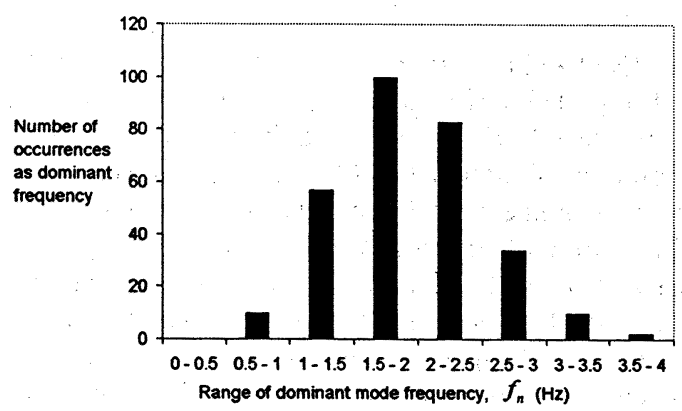

Figure 3. Histogram of frequency of dominant mode.

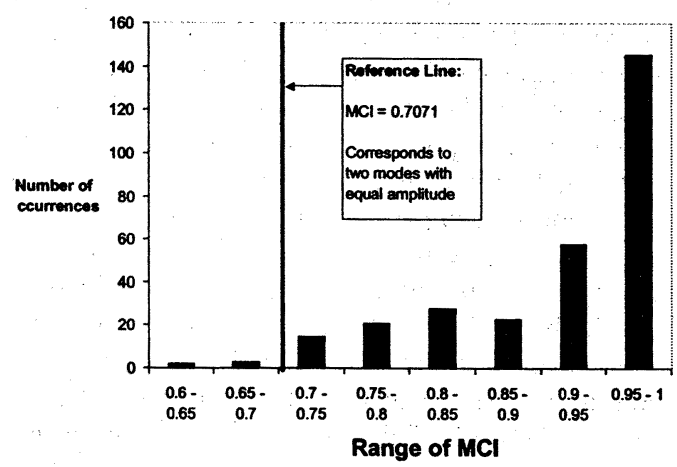

Figure 4. Histogram of Modal Contribution Index (MCI)

$$
S c=\frac{m\left|\zeta_{n, n e t}\right|}{\rho D^{2}}
$$

$m$ is the mass per length of the cable, $D$ is the diameter of the cable, and $\rho$ is the density of air. Fig. 5 shows the Scruton Number versus frequency of the dominant mode, with the number of the dominant mode indicated by the symbol. Note that all of the values are less than 10 , which suggests that the $S c>$ 10 criterion proposed by Irwin (1997) may indeed be adequate for rain-wind oscillation suppression.

\section{CABLE WITH LINEAR DAMPER}

In designing a damper for cable vibration suppression, it is necessary to determine the levels of sup- 


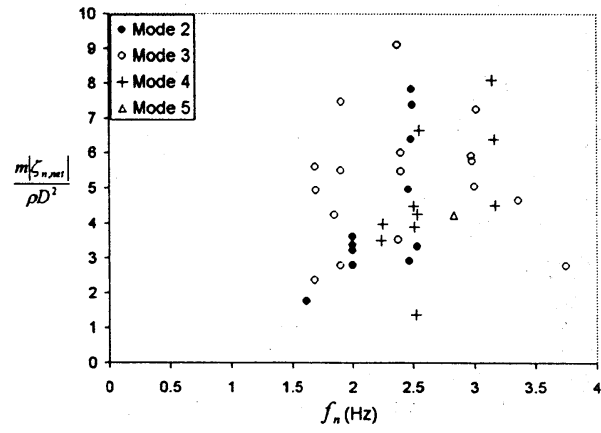

Figure 5. Normalized negative damping ratio vs. frequency of dominant mode

plemental damping provided in the first several modes of vibration for different values of the damper coefficient and different damper locations. In the case of taut cable with a linear viscous damper (Fig. 6), the supplemental damping ratios can be determined from a complex eigenvalue analysis of the damped cable in free vibration. An exact analytical formulation of the eigenvalue problem can be obtaining using the complex eigenfunctions of the damped cable (Krenk 2000; Main and Jones 2001a), yielding the following transcendental equation for the nondimensional eigenvalue $\lambda$

$$
\sinh (\pi \lambda)+\pi \frac{c}{m L \omega_{o 1}} \sinh \left(\pi \lambda \frac{\ell_{1}}{L}\right) \sinh \left(\pi \lambda \frac{\ell_{2}}{L}\right)=0
$$

in which $L$ is the length of the cable and $\omega_{o I}$ is the undamped fundamental natural frequency. (The dimensional eigenvalue is $\omega_{o 1} \lambda$.) Eq. (4) can be readily solved for the complex eigenvalues to obtain the modal damping ratios in as many modes as desired to an arbitrary degree of accuracy.

Previous numerical investigations revealed nondimensional groupings of parameters allowing the results to be presented as a very useful "universal estimation curve" of normalized modal damping ratio versus normalized damper coefficient, which is applicable in the first few modes for dampers located near the end of the cable (Pacheco et al. 1993) and allows easy determination of optimal design values. Krenk (2000) demonstrated that an explicit analytical equation for this universal curve could be obtained from the transcendental eigenvalue equation using asymptotic approximations.

The universal curve is plotted in Fig. 7, in which a

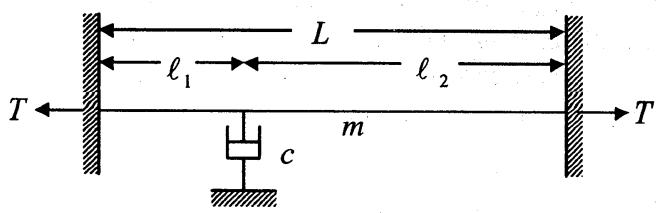

Figure 6. Taut cable with linear damper.

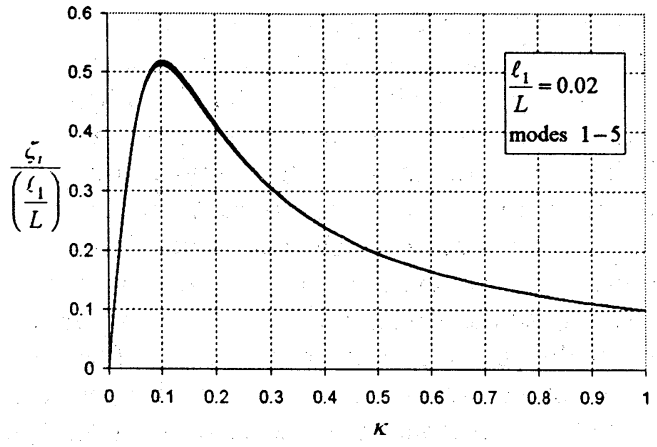

Figure 7. Universal estimation curve for linear damper

distinct curve has been plotted for the damping ratios in each of the first five modes for a damper location of $\ell_{l} / L=0.02$. The parameter $\kappa$ is defined as

$$
\kappa=\frac{c}{m L \omega_{o 1}} i \frac{\ell_{1}}{L}
$$

This analytical formulation of the complex eigenvalue problem can be readily used to explore the response of the cable-damper system in higher modes and for damper locations further from the end of the cable. In these cases, damping-induced frequency shifts are potentially significant, the universal curve of Fig. 7 is no longer adequate, and new, complex regimes of behavior are observed (Main and Jones 2001a). When the damper is located sufficiently near the antinode in a given mode, the damping ratio approaches critical as the damper coefficient approaches a critical value, $c \rightarrow 2 \sqrt{T m}$.

It is important to note that the optimal damping ratio can be achieved in only one mode of vibration in the case of a linear damper. If the damper is designed for optimal performance in a particular mode, it will be effectively more rigid in higher modes and more compliant in lower modes. In designing a linear damper, it is then necessary to select the mode in which optimal performance is desired, and the damping performance will be suboptimal in other modes. Figs. 2 and 3 indicate that rain-wind induced vibrations can occur over a fairly broad range of frequencies and mode numbers, and it is unclear how to identify the mode in which optimal performance should be achieved. In addition, designing a damper for optimal performance in a lower mode may leave it susceptible to other excitation mechanisms, such as vortex-induced vibrations, in higher modes.

\section{CABLE WITH NONLINEAR DAMPER}

Recent investigations by the authors, summarized in (Main and Jones 2001b), indicate that a nonlinear damper may overcome this limitation in performance of a linear damper, whereby optimal performance can be achieved in only one mode. The formu- 
lation of the complex eigenvalue problem for a taut cable with a linear damper can be extended to develop an approximate solution for the amplitudedependent effective damping ratios in the case of a nonlinear damper, in which the damper provides a dissipative force that is proportional to the cable velocity at the damper attachment point raised to an arbitrary positive exponent, $\beta$. This formulation reveals a nondimensional grouping of parameters that allows the "universal estimation curve" of normalized damping ratio versus normalized damper coefficient to be generalized to the case of a nonlinear damper. The shape of the curve is slightly different for each value of damping exponent, $\beta$, but for a given damping exponent the curve is nearly invariant with damper location and mode number over the same range of parameters as the universal estimation curve for the linear case. The parameter $\kappa$ is redefined as

$$
\kappa=\frac{c\left(\frac{A_{\tau}}{L}\right)^{\beta-1}}{m\left(L \omega_{o 1}\right)^{2-\beta}} i^{(2 \beta-1)}\left(\frac{\ell_{1}}{L}\right)^{\beta}
$$

which reduces to (5) in the case of a linear damper $(\beta=1)$. In the special case of $\beta=0.5$ (a square-root damper), it is observed that $\kappa$ is independent of mode number, so that the optimal damping ratio can be achieved in each mode at the same amplitude of oscillation. Fig. 8 shows a plot of normalized damping ratio versus $\boldsymbol{k}$ for a square-root damper. In designing a square-root damper, it is necessary to specify the amplitude of oscillation at which the optimal performance is desired in each mode; the damping performance degrades away from this optimal amplitude, but the damping performance is fairly robust with amplitude. The observation that the optimal damping performance can be achieved in more than one mode for a square-root damper suggests that it may be an effective option in the context of stay cable vibration suppression

\section{CLOSING REMARKS}

The phenomenon of stay-cable vibration has proved to be a challenging problem, both intellectually and practically over the past decade in particular. Considerable effort has been expended in wind tunnel investigations performed to help better understand the fundamental characteristics of the aerodynamic mechanism(s) at a "sectional" level. Relatively few investigations have focused on systemlevel observations and related attempts at mitigation. This abstract has presented a summary of an ongoing investigation using data from one cable-stayed bridge, as well as providing additional insight into one of the standard mitigation approaches: supple-

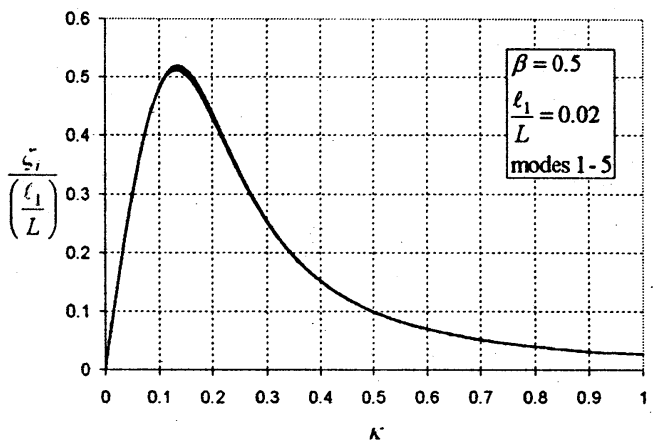

Figure 8. Estimation curve for square-root damper.

mental passive dampers. The full paper will expand upon these findings, presenting additional data, interpretation, and extensions of damper analyses.

\section{ACKNOWLEDGEMENTS}

The authors would like to acknowledge Texas Department of Transportation, the US Federal Highway Administration, the US Department of Defense (NDSEG Fellowship) and the Department of Civil Engineering at Johns Hopkins University for the support of various components of this work.

\section{REFERENCES}

1) Irwin, P. (1997). "Wind vibrations of cables on cable-stayed bridges." Proc. Struct Cong XV, 383387.

2) Jones, N.P. and Porterfield, M. (1997). "Measurement of Stay-Cable Vibration." Proc. Struct Con$g X V, 1290-1294$.

3) Krenk, S. (2000) "Vibrations of a taut cable with an external damper." J. App Mech, 67, 772-776.

4) Main, J.A. and Jones, N.P. (1999). "Full-scale measurements of cable vibration." Proc. $10^{\text {th }}$ Int Conf. on Wind Eng, 963-970.

5) Main, J.A. and Jones, N.P. (2001a). "Dynamic response of a taut cable with a linear viscous damper." JEng Mech, ASCE (in press).

6) Main, J.A. and Jones, N.P. (2001b). "Analysis and design of linear and nonlinear dampers for stay cables." Proc. $4^{\text {th }}$ Int. Symp Cable Dynamics, 309316.

7) Main. J.A., Jones, N.P., and Yamaguchi, H. (2001). "Characterization of rain-wind induced staycable vibrations from full-scale measurements." Proc. $4^{\text {th }}$ Int. Symp. Cable Dynamics, 235-242. 7) Pacheco, B.M., Fujino, Y., and Sulekh, A. (1993). "Estimation curve for modal damping in stay cables with viscous damper." J Struct Eng, 119(6), 1961-1979.

key words: stay-cable vibration, full-scale measurements, vibration suppression, damping 